\title{
Effect of plant and animal functional traits on nutrient cycling in low-input pastures
}

\author{
Dissertation \\ zur Erlangung des Doktorgrades \\ der Georg-August-Universität Göttingen
}

vorgelegt von

Thorsten Scheile

geboren in Steinfurt

Göttingen, September 2017 
1. Referent: Prof. Dr. Johannes Isselstein

2. Referentin: Prof. Dr. Nicole Wrage-Mönnig

Tag der mündlichen Prüfung: 17.11.2017 
,In the flinty light, it's midnight, and stars collide Shadows run, in full flight, to run, seek and hide I'm still not sure what part I play, in this shadow play, this shadow play. " Rory Gallagher, 1978 


\section{Contents}

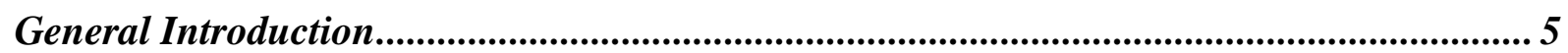

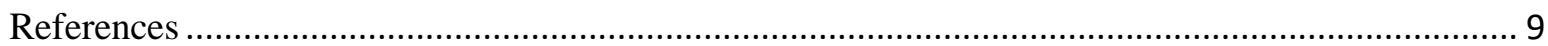

Herbage biomass and uptake under low-input grazing as affected by cattle and sheep

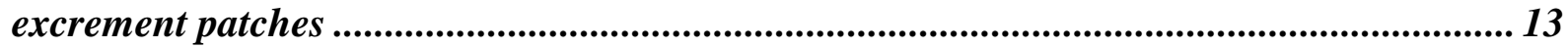

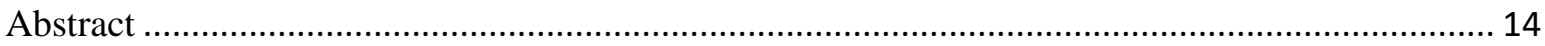

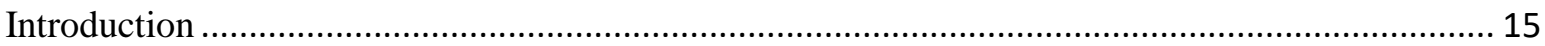

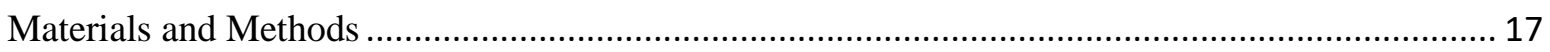

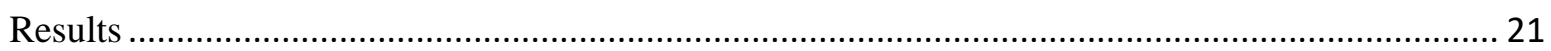

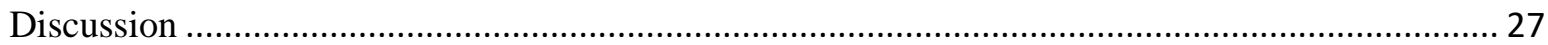

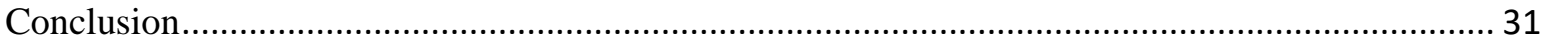

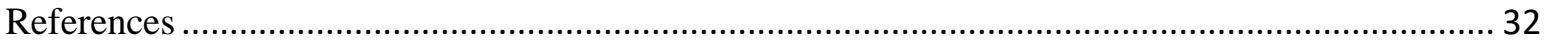

Plant biomass production and soil nutrient availability following different excrement application times in a low-input pasture ................................................................................... 37

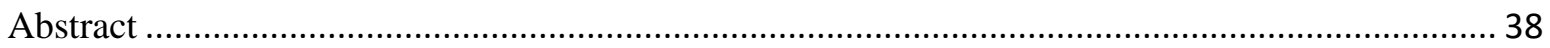

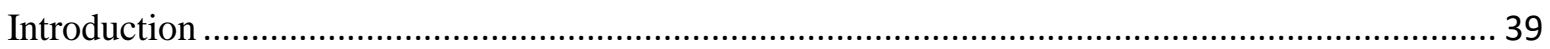

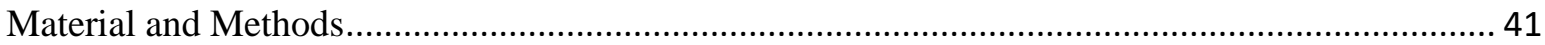

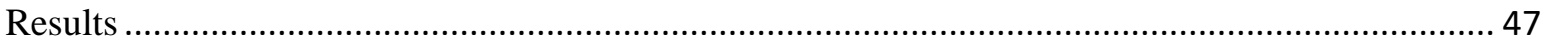

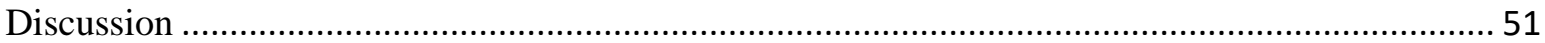

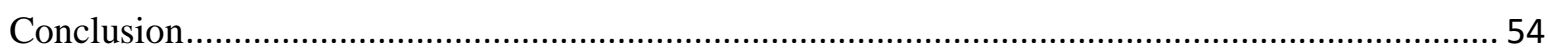

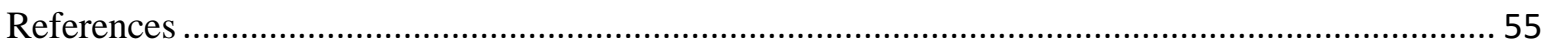

Small-scale sward heterogeneity rather than variable nutrient application rates in excrements determined plant nutrient concentration in a low-input pasture........................59

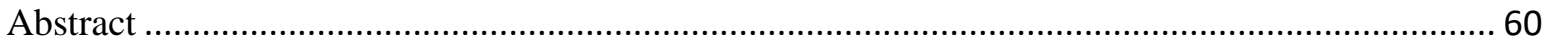

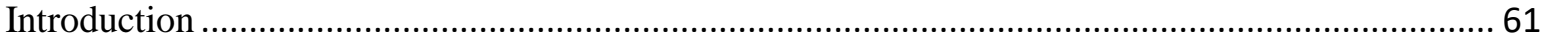

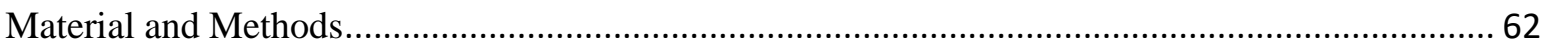

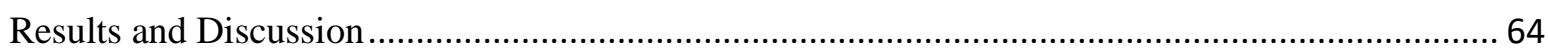

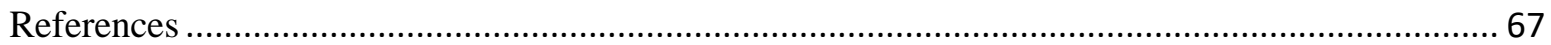

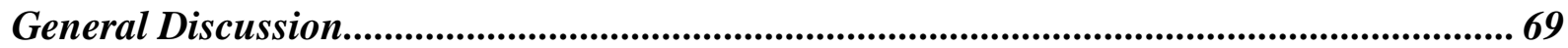

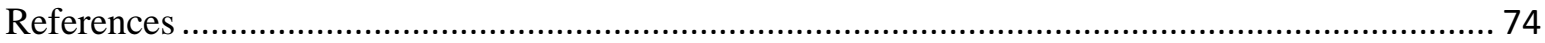

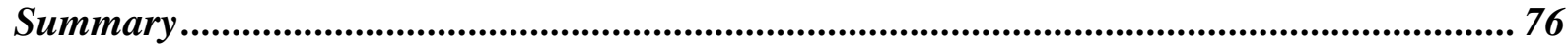

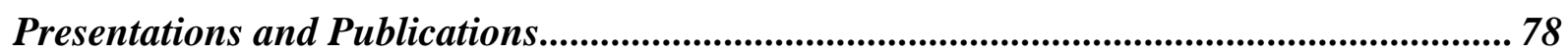

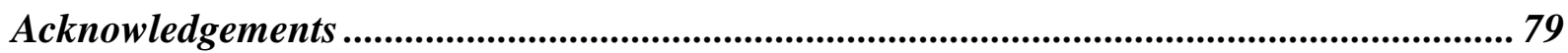




\section{General Introduction}

In Europe $30 \%$ of the agriculturally utilized area is permanent grassland (Smit et al., 2008). Semi-natural temperate grasslands are considered as a relevant resource of biodiversity in agriculture (Isselstein et al., 2005). Grazing has been recognized as the most efficient way to maintain and utilize these low-input and semi-natural grasslands (Rook et al., 2004; Wrage et al., 2011).

In grazed low-input pastures, which are mostly nitrogen $(\mathrm{N})$-limited, the absence of fertilizer use induces that nutrient cycling is primarily mediated by forage uptake and excrement deposition of grazing animals (Rotz et al., 2005). In this process specific characteristics of animal (e.g. grazing selectivity, size of excrement patches) and plant (e.g. height, specific leaf area index), so-called 'functional traits', play an important role for the cycling of nutrients within the system. Plant functional traits determine the plant response to available nutrients (Pastor \& Bridgham, 1999; Cingolani et al., 2005) and attractiveness to grazers (Bardgett \& Wardle, 2003). Animal functional traits influence the forage uptake (Lloyd et al., 2010), size and pattern of nutrient return (Williams \& Haynes, 1994).

Nutrient cycling through herbivores always leads to spatial separation and concentration of nutrients (Auerswald et al., 2010). Due to the low retention of nutrients of the ingested herbage in animal tissue, a high proportion of nutrients is recycled rather than removed from the grazing system (Rotz et al., 2005). Herbivores may excrete between 75 to $90 \%$ of N (Ball et al., 1979) and over $70 \%$ of phosphorus (P) consumed (Watson \& Foy, 2001). They quantitatively separate nutrients between urine and dung, whereby most of the $\mathrm{P}$ taken up is excreted in dung (over $70 \%$ ), potassium (K) predominantly in urine (up to 90\%) and $\mathrm{N}$ in differing proportions in both urine (45-80\%) and dung (20-55\%) (Whitehead, 2000). Under low-input conditions the N limitation may lead to a lower proportion of $\mathrm{N}$ being cycled in urine (Whitehead, 1995).

Urine and dung patches differ in their nutrient availability directly following the deposition (Haynes \& Williams, 1993; White-Leech et al., 2013a; Selbie et al., 2015). N in urine is primarily present in the form of urea, which is rapidly hydrolized and therefore plant-available shortly after deposition (Williams \& Haynes, 1994), while a high proportion $\mathrm{N}$ in dung is organically bound (White-Leech et al., 2013a) and mineralization can take up to two years 
(Saarijärvi \& Virkajärvi, 2009). Also K is readily available in urine, as it is water-soluble and in ionic form (Haynes \& Williams, 1993). Degradation of dung patches increases the P and K availability (Aarons et al., 2004).

The substantial differences between animal species in terms of size and redistribution of excrements over the pasture directly affect the nutrient cycling (Williams \& Haynes, 1994). Sheep urinate 18-20 times per day with a volume of 0.1-0.2 1 per urination, while cattle urinate less frequently (10-12 times) with a higher volume (1.6-2.2 1). The area covered by a single urination is 3.5 times greater for cattle than for sheep urine patches. Cattle may excrete 10-16 dung patches per day with a weight of 1.4-2.7 kg each, while sheep defecate more frequently (19-26 times) with a lower weight per defecation (0.03-0.17 kg) (Haynes \& Williams, 1993). The urine and dung patches represent a concentration of nutrients taken up from large grazing areas into the small areas covered by excrement (Afzal \& Adams, 1992). Excrements of grazing herbivores are considered as 'hot spots' of intensive nutrient cycling in these systems (Haynes \& Williams, 1993).

Apart from the animal functional traits, the grazing system is an important factor determining the distribution of excrements within the pasture (Dubeux et al., 2009; Auerswald et al., 2010). In continuously stocked pastures the excrements are locally concentrated near sheds and watering areas (Dubeux et al., 2006; Dubeux et al., 2009) and temporal evenly distributed (Dubeux et al., 2009). In rotationally grazed pastures, however, the pasture subdivision is suggested to limit this concentration and consequently redistribute excrements more evenly (Williams \& Haynes, 1990; Sigua et al., 2010). There is only little information on the pasture vegetation response to excrement deposition at different excrement deposition times (Bélanger et al., 2015).

Urine and dung were reported to affect both plant production and nutrient concentration following its deposition (Saarijärvi \& Virkajärvi, 2009; Moir et al., 2016). Urine patches can affect plant biomass production and nutrient concentration within a distance of $15-20 \mathrm{~cm}$ from the patch (Decau et al., 2003; Saarijärvi \& Virkajärvi, 2009; White-Leech et al., 2013a, b). In contrast to this, dung patches initially decrease biomass productivity at the surrounding area and over a long term increase biomass production following its deposition (MacDiarmid \& Watkin, 1971; Williams \& Haynes, 1995). Most studies were performed using cattle excrements, whereas only some information on the effect of sheep urine (Marsden et al., 2016) and sheep dung patches on pasture vegetation is available (Williams \& Haynes, 1995; Ma et 
al., 2007). Moreover, recent studies predominately focused on plant biomass $\mathrm{N}$ response to excrement patches, thus there is only little information on $\mathrm{P}$ and $\mathrm{K}$ in plant biomass (Aarons et al., 2009).

Most studies were performed on intensively managed and fertilized pastures (Saarijärvi \& Virkajärvi, 2009; White-Leech et al., 2013a), for which the additional nutrient supply with excrements is of minor importance for production of pasture vegetation. In low-input grazing systems the excrements markedly change the soil nutrient status at the patches (Aarons et al., 2009) and consequently affect the plant biomass nutrient concentration and production. Up to now only few studies investigated low-input pastures (Ma et al., 2007).

Diverse systems received less attention in recent studies. The sward botanical composition influences the response to nutrients. In species-rich, diverse pastures, the proportion of legumes and the amount of biologically fixed nitrogen can be decreased by nutrient addition through excrements, which offsets the effect of excrement-N input (Vinther, 1998), depending on clover content of the sward and time of excrement application (Ball et al., 1979; Ledgard et al., 1982). On species-poor swards the nutrient application leads to an increased biomass production (White-Leech et al., 2013a, b). Up to now there is no direct comparison of the response of grassdominated and diverse swards to excrements. In low-input pastures, which are rather diverse (Rook et al., 2004), this comparison would give more information on nutrient cycling in the system.

The excrement patches themselves also affect the plant-to-animal interaction in terms of local biomass uptake. Herbage growing in close vicinity to dung patches is avoided by grazing animals (Smith et al., 2009; Gillet et al., 2010). Avoidance of dung patches is a strategy of grazers to avoid parasite contamination (Smith et al., 2009). Pasture vegetation at urine patches may be preferentially grazed within the next grazing period (Jaramillo \& Detling, 1992), possibly due to increased nutrient concentration in the biomass. Differences between cattle and sheep in grazing selectivity at the excrement patches have rarely been studied (Forbes \& Hodgson, 1985). Results of Hutchings et al. (1998) show increasing biting depths of sheep near their dung patches with increasing age of the patches. Most studies on urine and dung effects on both vegetation production and grazing animal response have so far used simulated excrement patches, neglecting the conditions of a real grazing system. Under real grazing conditions, the response of pasture vegetation to excrements (production and nutrient-uptake response) is a complex process depending on defoliation frequency, defoliation severity and 
time of excrement deposition. Animal excrement deposition, as well as plant and animal response to excrement patches are therefore influenced and controlled by the grazing system. There is in particular a lack of information on animal species effect on plant functional group response to excrements and grazing response to excrement patches in dependence on plant functional groups present. So far the nutrient cycling from plant-to-animal, animal-to-soil and soil-to plant were individually investigated, thus a total view of animal-to-soil-to-plant in a grazing system is missing in current studies.

Therefore a rotational grazing system with cattle and sheep grazing on either grass-dominated or diverse swards was used, to analyse the influence of grazing animal species and sward botanical composition on herbivory effects on nutrient cycling (Chapter I). Based on these results a simulated grazing system was established, using excrements derived from the rotational grazing system, to further investigate the effect of nutrient separation in urine and dung on soil nutrient status and plant biomass (Chapter II). However, under realistic grazing conditions the nutrient concentration in excrements is variable (Haynes \& Williams, 1993), which is why it was additionally investigated, to what extent the plant biomass nutrient concentration responds to varying nutrient application rates with excrements (Chapter III).

The underlying questions of this work were:

$\rightarrow$ What is the effect of animal- and sward-specific responses to excrements on nutrient cycling within the stocking period subsequent to different excrement deposition times? (CHAPTER I)

$\rightarrow$ What is the medium-term effect of nutrient separation in urine and dung on plant biomass production and soil nutrient status (CHAPTER II)

$\rightarrow$ To what extent does the plant biomass nutrient concentration respond to varying excrement nutrient application rates present in a real grazing system? (CHAPTER III) 


\section{References}

Aarons, S.R., O'Connor, C.R. \& Gourley, C.J.P. 2004. Dung decomposition in temperate dairy pastures. I. Changes in soil chemical properties. Australian Journal of Soil Research, $42,107-114$.

Aarons, S.R., O’Connor, C.R., Hosseini, H.M. \& Gourley, C.J.P. 2009. Dung pads increase pasture production, soil nutrients and microbial biomass carbon in grazed dairy systems. Nutrient Cycling in Agroecosystems, 84, 81-92.

Afzal, M. \& Adams, W.A. 1992. Heterogeneity of soil mineral nitrogen in pasture grazed by cattle. Soil Science Society of America Journal, 56, 1160.

Auerswald, K., Mayer, F. \& Schnyder, H. 2010. Coupling of spatial and temporal pattern of cattle excreta patches on a low intensity pasture. Nutrient Cycling in Agroecosystems, $88,275-288$.

Ball, R., Keeney, D.R., Thoebald, P.W. \& Nes, P. 1979. Nitrogen balance in urine-affected areas of a New Zealand pasture. Agronomy Journal, 71, 309-314.

Bardgett, R.D. \& Wardle, D.A. 2003. Herbivore-mediated linkages between aboveground and belowground communities. Ecology, 84, 2258-2268.

Bélanger, G., Rochette, P., Chantigny, M., Ziadi, N., Angers, D., Charbonneau, É., Pellerin, D. \& Liang, C. 2015. Nitrogen availability from dairy cow dung and urine applied to forage grasses in eastern Canada. Canadian Journal of Plant Science, 95, 55-65.

Cingolani, A.M., Posse, G. \& Collantes, M.B. 2005. Plant functional traits, herbivore selectivity and response to sheep grazing in Patagonian steppe grasslands. Journal of Applied Ecology, 42, 50-59.

Decau, M.L., Simon, J.C. \& Jacquet, A. 2003. Fate of urine nitrogen in three soils throughout a grazing season. Journal of Environmental Quality, 32, 1405-1413.

Dubeux, J.C.B., Stewart, R.L., Sollenberger, L.E., Vendramini, J.M.B. \& Interrante, S.M. 2006. Spatial heterogeneity of herbage response to management intensity in continuously stocked pensacola bahiagrass pastures. Agronomy Journal, 98, 1453-1459. 
Dubeux, J.C.B., Sollenberger, L.E., Gaston, L.A., Vendramini, J.M.B., Interrante, S.M. \& Stewart, R.L. 2009. Animal behavior and soil nutrient redistribution in continuously stocked pensacola bahiagrass pastures managed at different intensities. Crop Science, 49, 1503-1510.

Forbes, T.D.A. \& Hodgson, J. 1985. The reaction of grazing sheep and cattle to the presence of dung from the same or the other species. Grass and Forage Science, 40, 177-182.

Gillet, F., Kohler, F., Vandenberghe, C. \& Buttler, A. 2010. Effect of dung deposition on smallscale patch structure and seasonal vegetation dynamics in mountain pastures. Agriculture, Ecosystems \& Environment, 135, 34-41.

Haynes, R.J. \& Williams, P.H. 1993. Nutrient cycling and soil fertility in the grazed pasture ecosystem. Advances in Agronomy, 49, 119-199.

Hutchings, M.R., Kyriazakis, I., Anderson, D.H., Gordon, I.J. \& Coop, R.L. 1998. Behavioural strategies used by parasitized and non-parasitized sheep to avoid ingestion of gastrointestinal nematodes associated with faeces. Animal Science, 67, 97-106.

Isselstein, J., Jeangros, B. \& Pavlu, V. 2005. Agronomic aspects of biodiversity targeted management of temperate grasslands in Europe - a review. Agronomy Research, 3, $139-151$.

Jaramillo, V.J. \& Detling, J.K. 1992. Small-scale heterogeneity in a semi-arid North American grassland. I. Tillering, $\mathrm{N}$ uptake and retranslocation in simulated urine patches. The Journal of Applied Ecology, 29, 1-8.

Ledgard, S.F., Steele, K.W. \& Saunders, W.H.M. 1982. Effects of cow urine and its major constituents on pasture properties. New Zealand Journal of Agricultural Research, 25, $61-68$.

Lloyd, K.M., Pollock M.L., Mason N.W.H. \& Lee W.G. 2010. Leaf trait-palatability relationships differ between ungulate species: Evidence from cafeteria experiments using native tussock grasses. New Zealand Journal of Ecology, 34, 219-226.

Ma, X., Wang, S., Jiang, G., Haneklaus, S., Schnug, E. \& Nyren, P. 2007. Short-term effect of targeted placements of sheep excrement on grassland in Inner Mongolia on soil and plant parameters. Communications in Soil Science and Plant Analysis, 38, 1589-1604. 
MacDiarmid, B.N. \& Watkin, B.R. 1971. The cattle dung patch. 1. Effect of dung patches on yield and botanical composition of surrounding and underlying pasture. Journal of the British Grassland Society, 26, 239-245.

Marsden, K.A., Jones, D.L. \& Chadwick, D.R. 2016. Disentangling the effect of sheep urine patch size and nitrogen loading rate on cumulative $\mathrm{N}_{2} \mathrm{O}$ emissions. Animal Production Science, 56, 265-275.

Moir, J., Cameron, K. \& Di, H. 2016. Potential pasture nitrogen concentrations and uptake from autumn or spring applied cow urine and DCD under field conditions. Plants, 5.

Pastor, J. \& Bridgham, S.D. 1999. Nutrient efficiency along nutrient availability gradients. Oecologia, 118, 50-58.

Rook, A.J., Dumont, B., Isselstein, J., Osoro, K., WallisDeVries, M.F., Parente, G. \& Mills, J. 2004. Matching type of livestock to desired biodiversity outcomes in pastures - a review. Biological Conservation, 119, 137-150.

Rotz, C.A., Taube, F., Russelle, M.P., Oenema, J., Sanderson, M.A. \& Wachendorf, M. 2005. Whole-farm perspectives of nutrient flows in grassland agriculture. Crop Science, 45 , 2139-2159.

Saarijärvi, K. \& Virkajärvi, P. 2009. Nitrogen dynamics of cattle dung and urine patches on intensively managed boreal pasture. The Journal of Agricultural Science, 147, 479491.

Selbie, D.R., Buckthought, L.E. \& Shepherd, M.A. 2015. The challenge of the urine patch for managing nitrogen in grazed pasture systems. Advances in Agronomy, 129, 229-292.

Sigua, G.C., Hubbard, R.K. \& Coleman, S.W. 2010. Quantifying phosphorus levels in soils, plants, surface water, and shallow groundwater associated with bahiagrass-based pastures. Environmental Science and Pollution Research, 17, 210-219.

Smit, H.J., Metzger, M.J. \& Ewert, F. 2008. Spatial distribution of grassland productivity and land use in Europe. Agricultural Systems, 98, 208-219.

Smith, L.A., White, P.C., Marion, G. \& Hutchings, M.R. 2009. Livestock grazing behavior and inter-versus intraspecific disease risk via the fecal-oral route. Behavioral Ecology, 20, 426-432. 
Vinther, F.P. 1998. Biological nitrogen fixation in grass-clover affected by animal excreta. Plant and Soil, 203, 207-215.

Watson, C.J. \& Foy, R.H. 2001. Environmental impacts of nitrogen and phosphorus cycling in grassland systems. Outlook on Agriculture, 30, 117-127.

Whitehead, D.C. 1995. Grassland nitrogen. CAB International Wallingford.

Whitehead, D.C. 2000. Nutrient elements in grassland: soil-plant-animal relationships. CAB International Wallingford.

White-Leech, R., Liu, K., Sollenberger, L.E., Woodard, K.R. \& Interrante, S.M. 2013a. Excreta deposition on grassland patches. I. Forage harvested, nutritive value, and nitrogen recovery. Crop Science, 53, 688-695.

White-Leech, R., Liu, K., Sollenberger, L.E., Woodard, K.R. \& Interrante, S.M. 2013b. Excreta deposition on grassland patches. II. Spatial pattern and duration of forage responses. Crop Science, 53, 1-8.

Williams, P.H. \& Haynes, R.J. 1990. Influence of improved pastures and grazing animals on the nutrient cycling within New Zealand soils. New Zealand Journal of Ecology, 14, $49-57$.

Williams, P.H. \& Haynes, R.J. 1994. Comparison of initial wetting pattern, nutrient concentrations in soil solution and the fate of ${ }^{15} \mathrm{~N}$-labelled urine in sheep and cattle urine patch areas of pasture soil. Plant and Soil, 162, 49-59.

Williams, P.H. \& Haynes, R.J. 1995. Effect of sheep, deer and cattle dung on herbage production and soil nutrient content. Grass and Forage Science, 263-271.

Wrage, N., Strodthoff, J., Cuchillo, H.M., Isselstein, J. \& Kayser, M. 2011. Phytodiversity of temperate permanent grasslands: Ecosystem services for agriculture and livestock management for diversity conservation. Biodiversity and Conservation, 20, 33173339. 
Chapter I:

Herbage biomass and uptake under low-input grazing as affected by cattle and sheep excrement patches

Scheile T., Isselstein J., Tonn B.

Published in Nutrient Cycling in Agroecosystems

DOI: 10.1007/s10705-018-9945-3 


\begin{abstract}
In low-input grazing systems excrement patches are the main nutrient input. They influence both forage production and intake of grazing animals. Our goals were to determine (1) whether seasons of differing weather conditions and swards of differing botanical composition influence the excrement effect on plant biomass in grazed pasture and (2) if animal species differ in their forage intake at excrement patches. We measured the plant biomass and forage intake responses to dung and urine patches of cattle and sheep in rotationally grazed low-input pastures with either grass-dominated or diverse swards in the stocking periods following excrement deposition in spring and autumn. At urine plots the plant biomass production was $14.7 \%$ higher than at the corresponding control plots, accompanied by a 19 and $17 \%$ higher biomass nitrogen and potassium concentration, respectively. The effect of excrements on plant biomass production, nutrient parameters and animal forage intake was not affected by animal species, sward type or stocking period. Small-scale sward height measurements showed that cattle avoided vegetation close to dung patches in both stocking periods whereas sheep did so only following the excrement deposition in spring and that cattle preferentially grazed at urine plots on grass-dominated swards. The effect of excrement patches on vegetation biomass parameters was small, which masked potential influences by animal species, sward type and excrement deposition time.
\end{abstract}

Keywords: Nutrient cycling; Grazing selection; Forage intake; Diverse grassland; Excreta; Patch 


\section{Introduction}

Grazing animals play an important role in the matter and nutrient cycle of pasture land, as most of the mineral nutrients consumed are returned to the pasture via dung and urine (Rotz et al. 2005). Urine and dung patches are considered as `hot spots` of intensive nutrient cycling in pastures, as ruminants predominantly excrete phosphorus $(\mathrm{P})$ in dung, potassium $(\mathrm{K})$ in urine and nitrogen $(\mathrm{N})$ in varying proportions in both urine and dung (Haynes \& Williams, 1993). Fertilized pastures, where the contribution of urine and dung to biomass productivity is less important, have been intensively investigated (Moir et al., 2013; Saarijärvi \& Virkajärvi, 2009; White-Leech et al., 2013a, b). Unfertilized low-input grazing systems, where excrement patches are the most important nutrient source for the pasture vegetation, have hardly been studied (Ma et al., 2007).

In contrast to dung, $\mathrm{N}$ in urine is present predominantly in rapidly hydrolized urea, which makes it plant-available shortly after deposition (Haynes \& Williams, 1993; White-Leech et al., 2013a). Consequently, time of excrement deposition could be crucial for plant utilization of the supplied nutrients (Moir et al., 2016). A deposition of highly plant-available $\mathrm{N}$ in phases of low nutrient demand, like over winter, may result in high nutrient losses (Saarijärvi \& Virkajärvi, 2009; Selbie et al., 2015). A direct comparison of different deposition times of urine and dung patches on plant biomass of grazed pastures has only rarely been made (Bélanger et al., 2015).

Apart from management, the botanical composition of the pasture is an important factor influencing the plant response to additional nutrient supply through excrement. Most studies have been performed on grass-dominated pastures, where the high $\mathrm{N}$ input from excrement leads to an increase in plant biomass productivity and $\mathrm{N}$ concentration (White-Leech et al., 2013a, b). In legume-rich pastures $\mathrm{N}$ input from excrement was shown to lead to a substitution of the fixed $\mathrm{N}$ and to decrease the legume dominance (Ledgard, 2001). So far, a direct comparison of excrement effects on grass-dominated and diverse swards, with their difference in $\mathrm{N}$ availability and demand, is missing.

Grazed pasture systems are characterised by a spatial variability in nutrient return in excrement patches, which leads to a spatial concentration, separation and redistribution of nutrients (Auerswald et al., 2010; Haynes \& Williams, 1993). Here the stocking rate is an important factor determining the excrement density in the paddock (Dennis et al., 2011). This factor was 
addressed by studies of the impact of animal species on nutrient cycling (Ma et al., 2007; WhiteLeech et al., 2013b; Williams \& Haynes, 1994). Especially at the sub-meter scale, the small excrement patches of smaller herbivores lead to a more fine-scale distribution of nutrients returned in comparison to larger herbivores. The effect of animal size on nutrient cycling has hardly been studied (Bakker et al., 2004; Williams \& Haynes, 1994). Cattle and sheep represent animal species of different excrement size and distribution (Haynes \& Williams, 1993). While urine patches of cattle and sheep can significantly increase plant biomass productivity and biomass N uptake (Decau et al., 2003; Marsden et al., 2016; Saarijärvi \& Virkajärvi, 2009; White-Leech et al., 2013a), cattle dung patches were shown to initially have a direct adverse effect on vegetation in the immediately affected area (White-Leech et al., 2013a; Williams \& Haynes, 1995). Information on the effect of sheep dung patches on plant biomass productivity is scarce (Ma et al., 2007; Williams \& Haynes, 1995), as is information on the effect of excrement on $\mathrm{P}$ and $\mathrm{K}$ concentration in the plant biomass. The mineral content of herbage is an important indicator of the nutrient supply to the plants and it contributes to the herbage nutritive value for grazers (Whitehead, 2000).

Excrement patches also have a direct effect on the local plant biomass intake by grazers. Herbage growing around dung patches is avoided by grazing herbivores (Gillet et al., 2010; Smith et al., 2009). In contrast, an increased plant biomass production, due to the high nitrate concentration at urine patches (Moir et al., 2012), may result in a preferred grazing of these areas within the following stocking period (Day \& Detling, 1990). To quantify the forage intake under grazing conditions, especially at dung patches, a small-scale resolution has to be chosen. The fine-scale height measurement (Stewart et al., 2001) of vegetation surrounding the excrement patches allows a precise assessment of excrement patch effects on animal grazing selectivity.

For these reasons, a grazing experiment on rotationally grazed pastures was performed using cattle and sheep as grazer species and grass-dominated and diverse swards to represent different botanical diversity of the pasture. Urine, dung and control (no excrement) patches were marked in situ in every paddock in spring and autumn of 2014 to determine the effect of excrement patches on herbage biomass production, nutrient concentration, plant nutrient uptake and forage intake by the grazers during the following stocking period. The underlying hypotheses of this study were (1) that urine and dung would increase plant biomass production and nutrient concentration to a different extent and with difference in the reaction of diverse and grass- 
dominated swards and, (2) that grazing animals reject dung patches and preferentially graze at urine patches, but that cattle and sheep differ in their grazing response to excrement patches.

\section{Materials and Methods}

Setup of the grazing experiment

The experimental site, an area of $6 \mathrm{ha}$, is a long-term permanent grassland in its initial condition corresponding to a moderately species rich Lolio-Cynosuretum. It is located in the Solling Uplands, Germany $\left(51^{\circ} 46^{\prime} 47 \mathrm{~N}, 9^{\circ} 42^{\prime} 11 \mathrm{E}\right)$; the altitude of the total area ranges from 184 to $209 \mathrm{~m}$ above sea level. The soil type is a Vertic Cambisol (World Reference Base of Soils), the texture is clayey/silty loam. Initial topsoil $(0-10 \mathrm{~cm})$ mean available nutrient concentrations in 2007 were P: 79, K: 174, Mg: $358 \mathrm{mg} \mathrm{kg}^{-1}$, mean pH was 6.8 (extraction: calcium acetate lactate for $\mathrm{P}$ and $\mathrm{K}, \mathrm{CaCl}_{2}$ for $\mathrm{Mg}$ and $\mathrm{pH}$; Seither et al., 2014). Topsoil total $\mathrm{N}$ and total $\mathrm{C}$ were 3 and $33 \mathrm{~g} \mathrm{~kg}^{-1}$, respectively (both in dry soil). The soil analyses indicated a sufficient supply with P and $\mathrm{K}$ (Janssens et al., 1998), whereas a positive plant yield response to $\mathrm{N}$ fertilization found by Seither et al. (2014) indicated $\mathrm{N}$ limitation. The average temperature was $8.2^{\circ} \mathrm{C}$ (1961-1990, Deutscher Wetterdienst, DWD, Location: Lutterbeck - $10 \mathrm{~km}$ from the experimental site at the same elevation). The average annual precipitation was $879 \mathrm{~mm}$ (1961-1990, Deutscher Wetterdienst, DWD, Location: Dassel - $3 \mathrm{~km}$ from the experimental site). Weather data during the experimental period is shown in Online Resource 1.

The experiment in its current form was established in 2012. In this experiment, two paddockscale factors were tested: botanical diversity of the pasture swards and the grazing animal species. The initial diversity of the sward was manipulated in 2006 and 2009 for a prior experiment with mixed grazing of cattle and sheep that ran from 2007-2011 (for further details see (Seither et al., 2014)). Following that experiment, the sward composition was again manipulated in 2012 by the use of herbicide against dicotyledonous plants (active components Fluroxypyr/ Triclopyr), resulting in a low-diversity grass-dominated sward ('grass sward') compared to the untreated 'diverse sward' (referred to as 'sward types' below). Before the start of the experiment the average contribution of plant functional groups to biomass were visually estimated as $93 \%$ grasses and $7 \%$ herbs at grass-dominated swards, with Dactylis glomerata, 
Poa trivialis, Poa pratensis, Lolium perenne and Festuca pratensis as the main species representing $>2 / 3$ of herbage dry mass. On diverse swards the average contribution of plant functional groups were $66 \%$ grasses, $31 \%$ herbs and $2 \%$ legumes, the main species being Dactylis glomerata, Poa trivialis, Poa pratensis, Taraxacum officinale and Lolium perenne representing $>2 / 3$ of herbage dry mass. Other species present can be found in Online Resource 2. Grazing animal species were cattle (adult, non-lactating suckler cows of the breed German Simmental), and sheep (adult, non-lactating Blackheaded sheep ewes). Animals were assigned to 0.5 ha paddocks. The stocking system was rotational stocking with three stocking periods per year. In each stocking period, the three experimental blocks (A, B, C) were grazed consecutively. The stocking density was based on the estimated daily animal dry matter intake, which is defined as the intake capacity (Jouven et al., 2008), to achieve a similar forage intake at each paddock for both animal species. The intake capacity is calculated from the metabolic bodyweight and condition of the animals. The number of sheep per paddock was chosen based on the intake capacity of cattle. The resulting stocking density per 0.5 ha paddock was 5 cattle, or 30 sheep, respectively. The stocking period lasted from early May to mid-October with a break of about 10 weeks for animal mating between stocking periods two and three (Online Resource 3).

\section{Marking of excrement and control plots}

To assess different scenarios of plant and animal response, effects of animal excrement were observed over two periods that differed in weather conditions and in the resting interval between stocking periods. The course of the experiment is shown in Table 1. The measurements followed a triplet design consisting of control, dung and urine plot. In each paddock, three urine patches were marked by direct animal observation at the end of the respective stocking period. In close vicinity to a marked urine patch, one dung and two control plots with the same botanical composition as on the urine patch were chosen. For sheep dung patches, visually recognisable droppings of approximately $100 \mathrm{~g}$ were chosen. If there was a visible influence of excrement on a marked control plot in the following stocking period, this control was discarded. Otherwise, one of the two controls was randomly chosen for further measurements. This resulted in a total of 108 sampled plots for the summer and 108 sampled plots for the winter observation period. 
These plots were fenced in a way that grazing within the fenced areas was possible but the contamination by excrement was prevented (Hirata et al., 1988). The fences consisted of four plastic poles connected with two wires in different heights. The resulting plot had an area of $1 * 1 \mathrm{~m}^{2}$ for cattle and $0.5^{*} 0.5 \mathrm{~m}^{2}$ for sheep, respectively (Online Resource 4 ). The plot size for cattle was chosen according to Hirata et al. (1988), with a ratio of 3.5 between the urine patch size (Haynes \& Williams, 1993) and the rest of the plot. The same ratio was used to determine the plot size based on the sheep urine patches, so that the results would be comparable between animal species.

Table 1 Dates for vegetation height measurement and vegetation biomass sampling at observation plots for the excrement deposition times

\begin{tabular}{ccc}
$\begin{array}{c}\text { Observation } \\
\text { period }\end{array}$ & $\begin{array}{c}\text { Marking of excrement and } \\
\text { control plots }\end{array}$ & $\begin{array}{c}\text { Vegetation height measurement and } \\
\text { plant biomass sampling }\end{array}$ \\
\hline Summer & $08 / 05-16 / 06 / 2014$ & $17 / 06-11 / 07 / 2014$ \\
Winter & $17 / 09 / 2014-27 / 10 / 2014$ & $11 / 05-09 / 06 / 2015$
\end{tabular}

Biomass sampling

Right before the stocking period that followed the selection of the excrement and control plots, one half of each plot was harvested at $2 \mathrm{~cm}$ height using electric scissors. The biomass of the other half was harvested after the stocking period. This led to the following target variables: Biomass production following excrement deposition (cut before animal re-grazing), forage residue (cut following animal re-grazing) and apparent forage intake (difference between the two cuts). The biomass was subsequently dried to constant weight for 48 hours at $60{ }^{\circ} \mathrm{C}$. After determining the dry matter (DM) weight, the material was ground to $1-\mathrm{mm}$. The $\mathrm{P}$ and $\mathrm{K}$ concentrations of the plant biomass were determined after digestion with aqua regia using an Inductively Coupled Plasma 6300 DUO ICP OMS (Thermo Fisher Corporation, Waltham). The analysis of $\mathrm{N}$ in plant biomass used the Dumas combustion method with a Variomax $\mathrm{CN}$ (Elementar Analysesysteme GmbH, Hanau). Plant nutrient uptake of aboveground biomass was calculated as the product of nutrient concentration and DM yield. 
The target variable of the vegetation height measurement was the stubble height. Vegetation height was measured in $5 \mathrm{~cm}$ intervals along previously defined transects (height $=$ height of the first plant part that touches a measuring surface of $6 \mathrm{~cm}^{2}$, as implemented by the sward stick; Stewart et al., 2001). Based on the excrement plots the height was measured in two directions at nine points each for cattle and at six points each for sheep, either starting in the centre of the plot (urine and control plots) or at the edge of the dung patches (Online Resource 4). The mean value of the height measurement of both transects with the same distance from the start of transect was used for further calculations. Stubble height was measured following the stocking period (measurement following animal re-grazing).

Stubble height gives a two-dimensional picture of the effect of excrement patches on the vegetation height as affected by the distance from the excrement itself. The absence of a distance effect on the target variable would indicate either a uniform reaction or no reaction to the excrement patches. An increasing vegetation height with increasing distance from the excrement would indicate a preference of the grazing animal, whereas a decreasing vegetation height with increasing distance from the excrement patch would indicate avoidance by the grazing animal. To account for variation of vegetation height that was independent of the deposition of excrement, the vegetation height of the corresponding control plots was subtracted from the vegetation height of each urine and dung plot at each distance.

\section{Statistical analyses}

The statistical analysis was carried out using the program $\mathrm{R}$ version 3.2.0 (R Core Team 2015). Influence of the four experimental factors plot type, observation period, sward type and animal species on the response variables were examined using linear mixed effects (LME) models and the package nlme (Pinheiro et al., 2015). LME models for plant biomass production, nutrient concentration and plant nutrient uptake had the fixed effects patch type, observation period, sward type and animal species, as well as their interactions, and replicate blocks with nested paddock and triplet locations of patch types as the random effects. For the statistical analysis of the vegetation height, each excrement type was tested separately for the two animal species. 
Initial LME models had the distance from excrement patch, sward type and observation period as fixed effects and replicate block as the random effect. All residuals were checked for normal distribution and homogeneity of variance. Because of heterogeneous variances, a boxcox function was run for plant biomass production and forage residue in order to determine the appropriate transformation using the MASS package (Venables \& Ripley, 2002). Initial LME models were simplified by removing non-significant factors or interactions, if this led to a lower value of the second-order Akaike Information Criterion (AICc). The pair-wise comparison of means in the case of significant fixed effects was performed using the LSD test as implemented in the package lsmeans (Lenth \& Hervé, 2015).

\section{Results}

\section{Plant biomass}

The statistical analysis showed a significant effect of plot type on plant biomass production (Fig. 1a). Harvested biomass was increased by $14.7 \%$ at the urine plots, as compared to the corresponding control plots. The plant biomass production was neither affected by animal species, nor by observation period or sward type (Table 2).
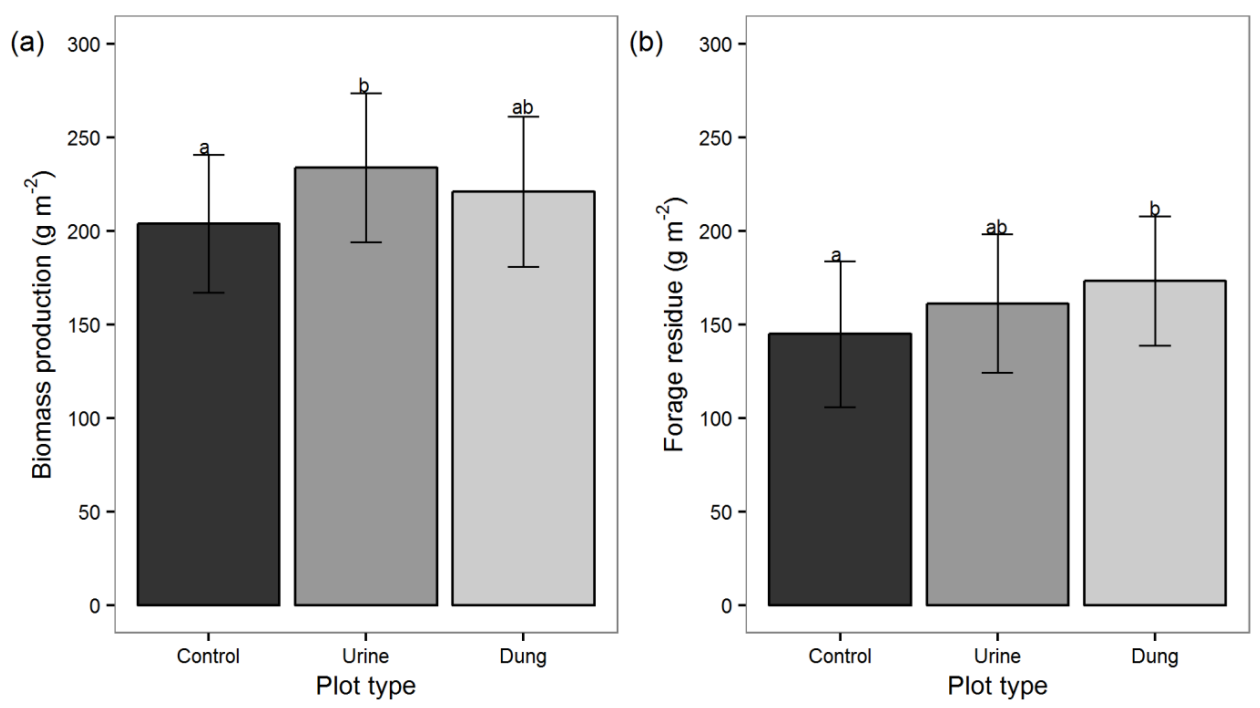
Figure 1 Mean ( \pm standard error, $n=72$ ) plant biomass production (a) and forage residue (b) of different plot types, averaged across grazing animal species, observation periods and sward types. Means with different letters indicate significant differences between patch types (linear mixed effect models with Tukey LSD test at $P<0.05$ ).

Table 2 Effects of plot type (urine patch, dung patch, control) on the vegetation dry matter biomass production, apparent animal forage uptake and forage residue following the stocking period, as affected by grazing animal species (cattle or sheep), sward type (grass-dominated or diverse) and observation period (summer or winter); values represent the results of the linear mixed effects models ( $\mathrm{F}$ and $P$ ); main effects and interactions for which no values are presented were not included in the simplified final linear mixed effects model.

\begin{tabular}{ccccccc}
\hline Effect & \multicolumn{2}{c}{ Biomass production } & \multicolumn{2}{c}{ Apparent forage uptake } & \multicolumn{2}{c}{ Forage residue } \\
& $F$ & $P$ & $F$ & $P$ & $F$ & $P$ \\
Plot type (P) & 3.74 & $\mathbf{0 . 0 2 5 5}$ & & & 4.62 & $\mathbf{0 . 0 1 1}$ \\
Sward (S) & & & 4.73 & 0.061 & 1.41 & 0.236 \\
Animal (A) & & & & 2.94 & 0.124 \\
Observation period (O) & & & 0.30 & 0.583 & 3.70 & 0.055 \\
S x O & & 9.42 & $\mathbf{0 . 0 0 2}$ & 12.60 & $<\mathbf{0 . 0 0 1}$ \\
A x O & & & & 3.01 & 0.084 \\
\hline
\end{tabular}

Significant effects are highlighted in bold

Apparent forage intake was neither affected by plot type, nor by animal species. Only a significant sward type*observation period-interaction $(P<0.05)$ was found, showing a significantly higher amount of biomass taken up in grass-dominated swards in the winter observation period $\left(71.8 \mathrm{~g} \mathrm{~m}^{-2}\right)$ than in the summer observation period $\left(15.7 \mathrm{~g} \mathrm{~m}^{-2}\right)$. The biomass taken up in diverse swards was $78.1 \mathrm{~g} \mathrm{~m}^{-2}$ in summer and $69.5 \mathrm{~g} \mathrm{~m}^{-2}$ in winter observation period respectively (data not shown).

Forage residue (Fig. 1b) was significantly affected by the plot type. We found more biomass remaining at dung than at control plots. The forage residue was not affected by animal species. Like apparent forage intake, the forage residue was significantly affected by the sward type*observation period-interaction. More plant biomass was left in the grass-dominated swards in summer $\left(196.1 \mathrm{~g} \mathrm{~m}^{-2}\right)$ observation period than in winter observation period (130.9 $\mathrm{g}$ $\mathrm{m}^{-2}$ ). In the diverse swards, $149.9 \mathrm{~g} \mathrm{~m}^{-2}$ were left in summer and $163.8 \mathrm{~g} \mathrm{~m}^{-2}$ in winter observation period. 
Animal response is shown as the stubble height difference to the corresponding control plots. Only models including a significant effect of distance to the excrement on stubble height were included for further consideration (Table 3).

Table 3 Vegetation height of dung and urine plots adjusted for the height of control plots as affected by distance along a transect from the excrement, sward type (grass-dominated or diverse) and observation period (summer or winter); stubble height: vegetation height at the end of the stocking period following the one during which excrement were deposited; values represent the results of the linear mixed effects models (F and $P$ ); main effects and interactions for which no values are presented were not included in the simplified final linear mixed effects model.

\begin{tabular}{|c|c|c|c|c|c|c|c|c|}
\hline \multirow[t]{4}{*}{ Effect } & \multicolumn{8}{|c|}{ Stubble height } \\
\hline & \multicolumn{4}{|c|}{ Cattle } & \multicolumn{4}{|c|}{ Sheep } \\
\hline & \multicolumn{2}{|c|}{ Urine } & \multicolumn{2}{|c|}{ Dung } & \multicolumn{2}{|c|}{ Urine } & \multicolumn{2}{|c|}{ Dung } \\
\hline & $F$ & $P$ & $F$ & $P$ & $F$ & $P$ & $F$ & $P$ \\
\hline Distance (D) & 0.20 & 0.648 & 46.16 & $<0.001$ & 3.97 & 0.050 & 11.00 & 0.001 \\
\hline Sward (S) & 4.87 & 0.029 & 7.81 & 0.006 & 7.30 & 0.0 & & 0.687 \\
\hline $\begin{array}{l}\text { Observation } \\
\text { period }(\mathrm{O})\end{array}$ & 11.28 & 0.001 & 10.31 & 0.001 & 11.18 & 0.0 & & 0.674 \\
\hline$D \times S$ & 5.54 & 0.020 & & & & & & \\
\hline $\mathrm{D} \times \mathrm{O}$ & & & 9.94 & 0.002 & & & 4.83 & 0.031 \\
\hline $\mathrm{S} \times \mathrm{O}$ & & & & & 27.15 & $<0.001$ & 9.72 & 0.002 \\
\hline
\end{tabular}

Significant effects are highlighted in bold

Stubble height at cattle urine and dung plots was affected by distance from the excrement patch (Fig. 2a, b). The urine plots showed a significant distance*sward type-interaction, as less vegetation was left in the centre of grass-dominated swards for both observation periods. The diverse swards were grazed to a similar height across the whole measurement transect. The distance effect at the dung plots of cattle differed between the two observation periods. In the summer observation period, cattle left a higher stubble, particularly in close vicinity to the patch. For the winter observation period the reaction was less pronounced, but still visible. 
For the stubble height at the dung plots under sheep grazing, the distance*observation periodinteraction was significant. While the avoidance of biomass in dung plots was clearly visible for the summer observation period, particularly in close vicinity of the dung patch, there was no such response in the winter observation period (Fig. 2c). No distance-effect and therefore no spatial grazing response was found at the sheep urine plots.
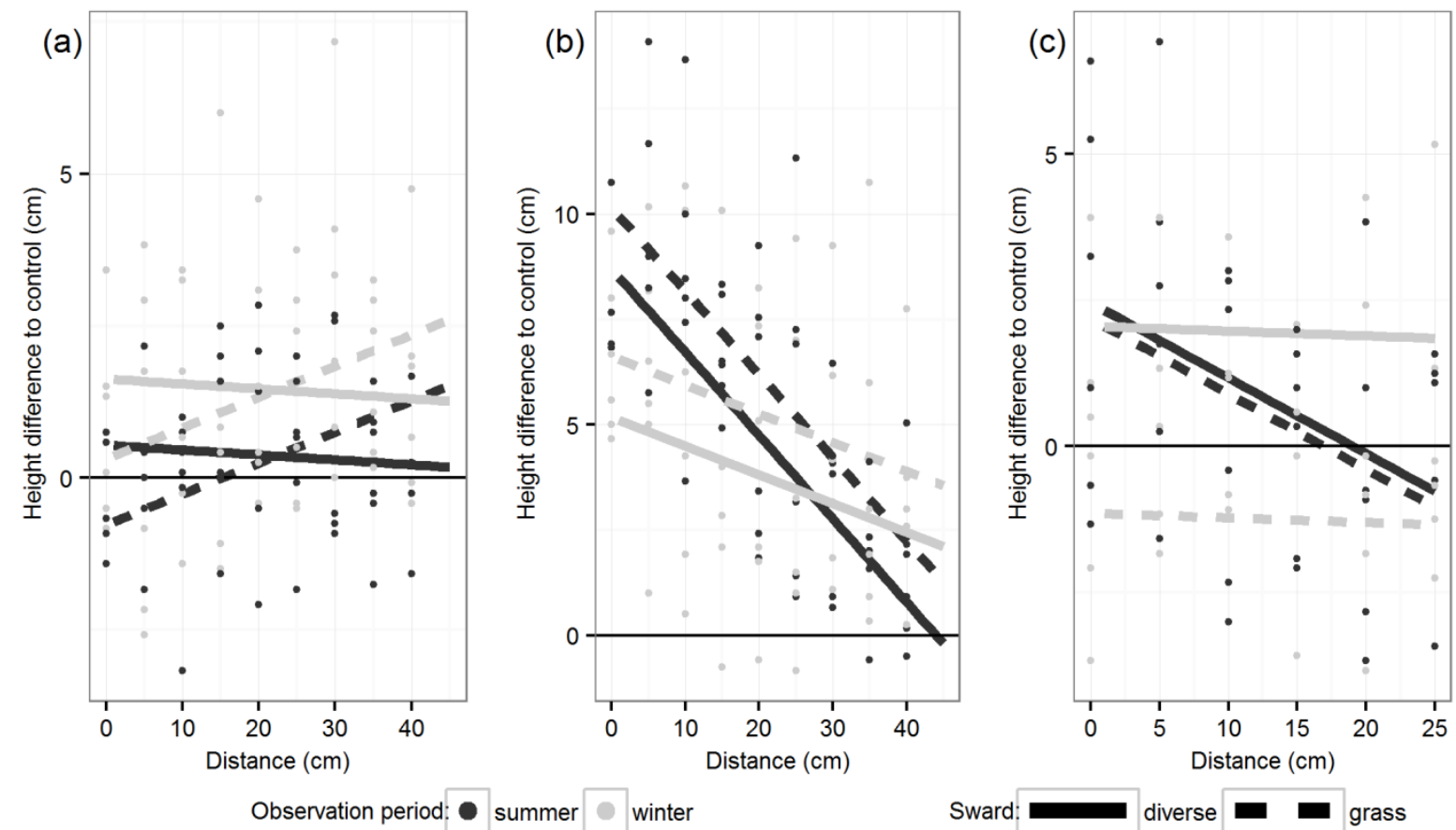

Figure 2 Vegetation height difference in relation to the control (no excrement) with distance from the excrement patches, vegetation stubble height following the stocking period on cattle urine plots (a), cattle dung plots (b), sheep dung plots (c).

Nutrient concentration and nutrient uptake of plant biomass and apparent animal nutrient intake

The statistical analysis of the nutrient concentration in sampled plant biomass of the first cut is shown in Table 4 and Figure 3a. The mean $\mathrm{N}$ and $\mathrm{K}$ concentration in plant biomass was $17 \mathrm{~g}$ $\mathrm{kg}^{-1}$ and $23 \mathrm{~g} \mathrm{~kg}^{-1}$, respectively.

The $\mathrm{N}$ uptake of plant biomass was significantly increased (Fig. 3b) at urine compared to control plots. Furthermore, the K uptake (Fig. 3c) of sampled biomass was significantly increased, 
compared to the control, by both dung and urine. The P uptake was not affected by the different excrement plots.

The apparent $\mathrm{N}$ intake by grazing animals (Fig. 3d) was significantly higher at the urine plots in comparison to the control and dung plots. Furthermore the apparent $\mathrm{K}$ intake (Fig. 3e) was significantly higher at the urine plots. The different plot types had no effect on the P intake.
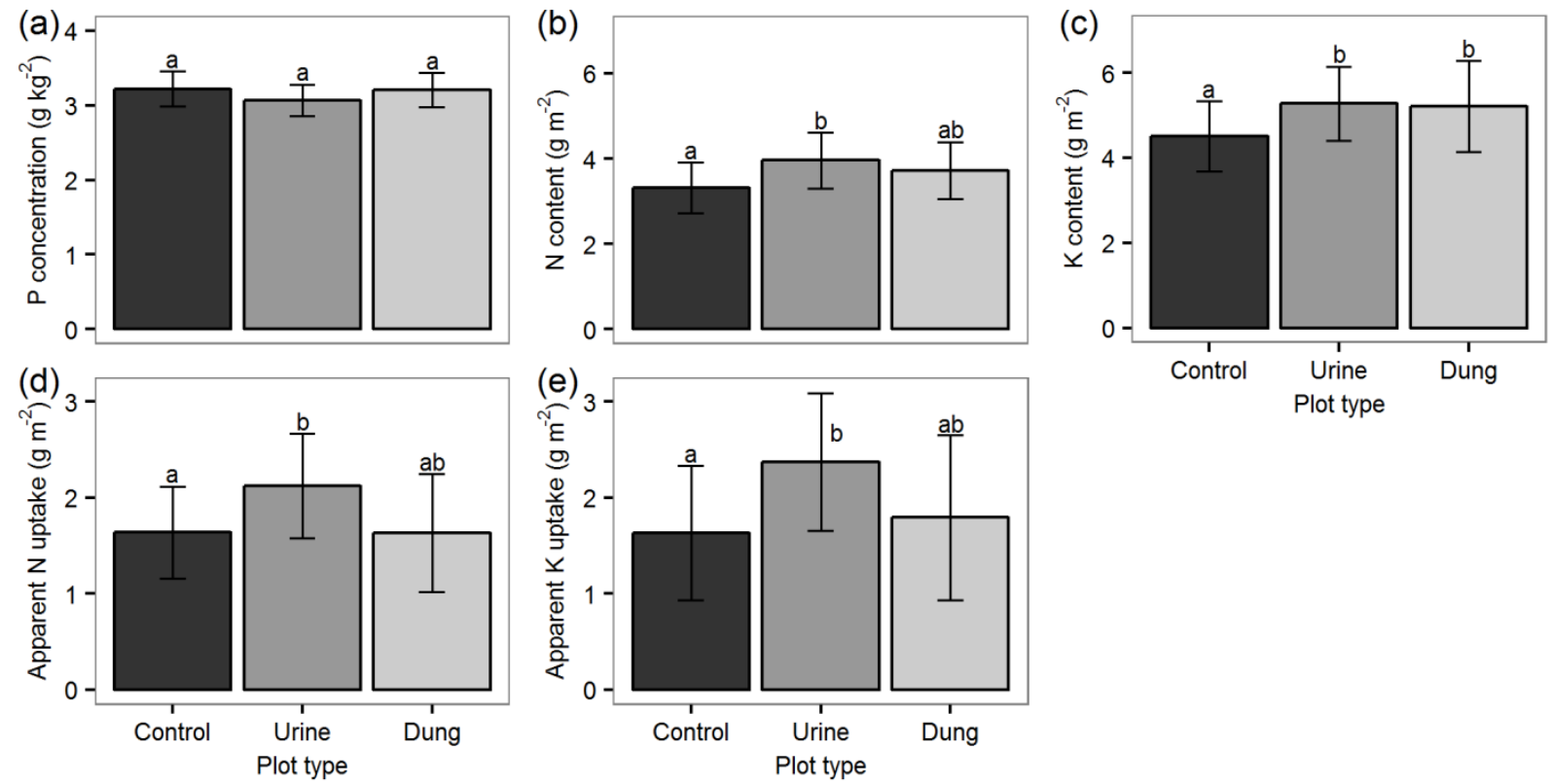

Figure 3 Mean ( \pm standard error, $n=72$ ) plant biomass P concentration (a) N uptake (b), K uptake (c), apparent animal $\mathrm{N}$ intake (d) and apparent animal $\mathrm{K}$ intake on different plot types, averaged across grazing animal species, observation periods and sward types. Means with different letters indicate significant differences between patch types (linear mixed effects models with Tukey LSD test at $P<0.05$ ). 


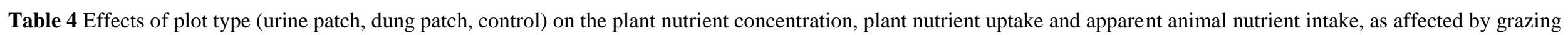

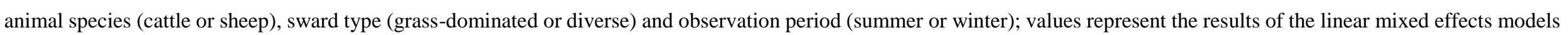
$(F$ and $P$ ); main effects and interactions for which no values are presented were not included in the simplified final linear mixed effects model.

\begin{tabular}{|c|c|c|c|c|c|c|c|c|c|c|c|c|c|c|c|c|c|c|}
\hline \multirow{3}{*}{ Effect } & \multicolumn{6}{|c|}{ Nutrient concentration } & \multicolumn{6}{|c|}{ Nutrient content in plant biomass } & \multicolumn{6}{|c|}{ Apparent animal nutrient uptake } \\
\hline & \multicolumn{2}{|c|}{$\mathrm{N}$} & \multicolumn{2}{|c|}{$\mathrm{P}$} & \multicolumn{2}{|c|}{$\mathrm{K}$} & \multicolumn{2}{|c|}{$\mathrm{N}$} & \multicolumn{2}{|c|}{$\mathrm{P}$} & \multicolumn{2}{|c|}{$\mathrm{K}$} & \multicolumn{2}{|c|}{$\mathrm{N}$} & \multicolumn{2}{|c|}{$\mathrm{P}$} & \multicolumn{2}{|c|}{$\mathrm{K}$} \\
\hline & $F$ & $P$ & $F$ & $P$ & $F$ & $P$ & $F$ & $P$ & $F$ & $P$ & $F$ & $P$ & $F$ & $P$ & $F$ & $P$ & $F$ & $P$ \\
\hline Plot type (P) & & & 3.36 & 0.036 & & & 3.65 & 0.027 & 2.50 & 0.084 & 4.10 & 0.018 & 3.22 & 0.042 & & & 3.85 & 0.023 \\
\hline Sward (S) & 1.41 & 0.278 & 23.20 & 0.001 & 8.92 & 0.017 & 2.77 & 0.134 & & & & & 4.66 & 0.062 & 5.11 & 0.053 & & \\
\hline Animal (A) & 0.10 & 0.753 & & & & & & & & & & & & & & & & \\
\hline $\begin{array}{l}\text { Observation } \\
\text { period }(\mathrm{O})\end{array}$ & 104.92 & $<0.001$ & 73.81 & $<0.001$ & 3.70 & 0.055 & 21.85 & $<0.001$ & 4.72 & 0.031 & & & 5.83 & 0.016 & 3.74 & 0.054 & & \\
\hline $\mathrm{P} \times \mathrm{O}$ & & & & & & & & & & & & & 2.85 & 0.060 & & & & \\
\hline $\mathrm{S} \times \mathrm{A}$ & 0.01 & 0.896 & & & & & & & & & & & & & & & & \\
\hline $\mathrm{S} \times \mathrm{O}$ & 7.59 & 0.006 & 13.75 & $<0.001$ & 11.63 & $<0.001$ & & & & & & & & & 8.02 & 0.005 & & \\
\hline $\mathrm{A} \times \mathrm{O}$ & 11.54 & $<0.001$ & & & & & & & & & & & & & & & & \\
\hline $\mathrm{S} \times \mathrm{A} \times \mathrm{O}$ & 5.40 & 0.021 & & & & & & & & & & & & & & & & \\
\hline
\end{tabular}




\section{Discussion}

Effect of excrement on plant biomass production, nutrient concentration and nutrient uptake

Contrary to our first hypothesis, there was no interactive effect between the patch types and the other experimental factors on either biomass production, nutrient concentration or nutrient uptake. Urine deposition led to an increased plant biomass production as well as increased biomass $\mathrm{N}$ and $\mathrm{K}$ uptake. However, plant biomass production at these patches, which usually represent an input of highly plant available nutrients and thus distinctly increase plant biomass (Selbie et al., 2015), was much lower than found in other studies. Average increases of plant biomass production by $25-40 \%$ relative to the control have been reported for urine patches of cattle and sheep (Marsden et al., 2016; White-Leech et al., 2013a; Williams \& Haynes, 1994). Similarly, the $\mathrm{N}$ concentrations of $17 \mathrm{~g} \mathrm{~kg}^{-1}$ found in the herbage growing at the excrement patches were far below the values of 21-43 $\mathrm{g} \mathrm{kg}^{-1}$ reported by others (Moir et al., 2013; WhiteLeech et al., 2013b), whereas the $\mathrm{K}$ concentration of $23 \mathrm{~g} \mathrm{~kg}^{-1}$ was within the range reported (Kayser et al., 2007). Dung patches neither affected biomass production nor $\mathrm{N}$ uptake, even though the decomposition of the dung patches during the winter observation period implied a possible mineralization of organic $\mathrm{N}$ in dung and hence an increase of plant available $\mathrm{N}$ (Deenen \& Middelkoop, 1992; Haynes \& Williams, 1993). The increase in plant K uptake and a slightly higher plant biomass $\mathrm{P}$ concentration in the dung plots are in line with other findings and can be ascribed to a high quantity of plant available inorganic $\mathrm{P}$ and soluble $\mathrm{K}$ in dung (Aarons et al., 2009; Whitehead, 2000).

Assuming average nutrient concentrations of $5 \mathrm{~g} \mathrm{l}^{-1} \mathrm{~N}$ and $8 \mathrm{~g} \mathrm{l}^{-1} \mathrm{~K}$ in urine, 21 urine per cattle and 0.21 urine per sheep urine patch (Haynes \& Williams, 1993), cattle and sheep urine plots would have received 10 and $4 \mathrm{~g} \mathrm{~m}^{-2} \mathrm{~N}$ and 16 and $6.4 \mathrm{~g} \mathrm{~m}^{-2} \mathrm{~K}$, respectively. Similarly, assumed dung nutrient concentrations of $29 \mathrm{~g} \mathrm{~kg}^{-1} \mathrm{~N}, 12 \mathrm{~g} \mathrm{~kg}^{-1} \mathrm{P}$ and $8 \mathrm{~g} \mathrm{~kg}^{-1} \mathrm{~K}$ (Haynes \& Williams, 1993) and average dung patch weights of $2000 \mathrm{~g}$ for cattle and $100 \mathrm{~g}$ for sheep (Haynes \& Williams, 1993) imply nutrient inputs of $58 \mathrm{~g} \mathrm{~m}^{-2} \mathrm{~N}, 24 \mathrm{~g} \mathrm{~m}^{-2} \mathrm{P}$ and $16 \mathrm{~g} \mathrm{~m}^{-2} \mathrm{~K}$ on cattle and $2.9 \mathrm{~g} \mathrm{~m}^{-2} \mathrm{~N}, 1.2 \mathrm{~g} \mathrm{~m}^{-2} \mathrm{P}$ and $0.8 \mathrm{~g} \mathrm{~m}^{-2} \mathrm{~K}$ on sheep dung plots, respectively. The weak plant productivity and nutrient uptake responses to urine and dung suggests that these nutrients were not efficiently used by the plants. Potential reasons include species composition, growth 
limitation caused by nutrients other than $\mathrm{N}, \mathrm{P}$ or $\mathrm{K}$ and weather conditions that either limited plant growth or promoted nutrient losses.

Moir et al., (2013) found great differences between thirteen common grass species in their ability to utilize the high level of $\mathrm{N}$ input found in urine patches. For the three most frequent species in our study (see Online Resource 2), they observed an above average shoot biomass increase in response to $\mathrm{N}$ application for Dactylis glomerata, while $\mathrm{N}$ response of Poa pratensis was below average, and that of Lolium perenne depended on the cultivar used (Moir et al., 2013). Even though all three species are high-yielding grasses that are frequently sown in leys (Kirwan et al., 2007), the genotypes at the study site do not represent commercially used cultivars. They may be adapted to relatively low levels of nutrient availability and less able to exploit high nutrient inputs.

At the experimental site, other nutrients than N, P or K are unlikely to limit plant growth. Boron $\left(0.01 \mathrm{mg} \mathrm{g}^{-1}\right)$ and sulphur concentration (1.34 $\left.\mathrm{mg} \mathrm{g}^{-1}\right)$ measured in plants on an adjacent plot with the same management histories (unpublished data) as well as soil $\mathrm{pH}$ and soil extractable $\mathrm{Mg}$ concentrations point towards a sufficient availability of these elements.

Weather was generally favourable for plant growth during the two observation periods. Monthly average temperatures were very close to long-term averages from May to July in both years and $1-2{ }^{\circ} \mathrm{C}$ warmer than the long-term average in the months January to April 2014 and September 2014 to January 2015. Together with average or above long-term average precipitation from January to July 2014, this provided good growing conditions during the summer observation period. Only for the winter observation period, sub-average precipitation in the two months preceding the sampling might have limited biomass production. High precipitation rates directly following the excrement deposition in spring and autumn could have increased $\mathrm{N}$ leaching below the active root zone (Cameron et al., 2013) and thus lowered the plant available $\mathrm{N}$ at the excrement patches. Additionally, nutrient leaching losses over winter usually lead to a seasonal variation in pasture reaction to the excrement in the following year (Moir et al., 2011). Precipitation from October 2014 to March 2015 was 439 mm, which was $38 \%$ higher than the long-term average, potentially increasing $\mathrm{N}$ leaching over winter. Nevertheless, the effect of urine on nutrient uptake did not differ between summer and winter observation periods. A closer consideration of nutrient losses at the excrement patches may be an approach for further investigations on the fate of nutrients. 
Leaching may partly explain the lack of differences in urine effects between cattle and sheep. Given the sampling plot size chosen in our study, the per-area amount of nutrients returned to the pasture should have been higher at cattle than at sheep urine plots (see above) and thus should have resulted in a higher plant biomass production. A greater potential of the larger cattle urine patches to loose $\mathrm{N}$ (Orwin et al., 2009) may have decreased animal-specific differences in plant biomass $\mathrm{N}$ uptake at the urine plots.

Contrary to our first hypothesis, the response of biomass production, $\mathrm{N}$ concentration or $\mathrm{N}$ uptake to excrement deposition did not differ between diverse and grass-dominated swards. For low-N sites, legume dominance has been shown to decline due to $\mathrm{N}$ return in excrement (Ledgard, 2001), partly counteracting the effect of this $\mathrm{N}$ return on biomass production and $\mathrm{N}$ concentration. The legume content was low in the diverse sward of our study, but their higher herbage proportion should also have affected the $\mathrm{N}$ uptake at the excrement plots.

Biomass production, nutrient concentration and nutrient uptake were also characterised by a great variability within experimental treatments.

Most of the existing research on urine and dung effects has been performed under simulated pasture conditions using artificially placed excrement and, in some cases, artificial urine.

In contrast to these experiments, studying excrement effects in grazed pastures induces several additional sources of variation: Nutrient concentrations in cattle and sheep urine can range widely between 2-11 $\mathrm{g} \mathrm{l}^{-1} \mathrm{~N}$ and 7-9 $\mathrm{g} \mathrm{l}^{-1} \mathrm{~K}$ (Haynes \& Williams, 1993; Whitehead, 2000), with considerable variation even within the same animal (Hoogendoorn et al., 2010). Somewhat smaller ranges of nutrient concentration have been reported for dung of cattle and sheep, with 2.3-2.9 \% N and 0.7-0.8 \% K and 0.7-1.2 \% P in dung DM (Whitehead, 2000). Additionally, both the amount of urine and dung per excrement deposition and the area covered by each excrement patch are highly variable for both cattle and sheep (Haynes \& Williams, 1993). Finally, grazing selectivity leads to heterogeneous swards containing plants in different states of regrowth, which can be expected to vary in their reaction to nutrient input. The variability observed in our results gives a new insight into the complexity of pasture response to excrement under real grazing conditions. 
In general, herbivores avoid grazing swards contaminated with faeces as a method of parasite avoidance (Smith et al., 2009). Even though the forage residue (Fig. 1b) did not differ between animal species, vegetation height measurement in close vicinity to the dung patches revealed a distinct difference in dung avoidance between cattle and sheep (Fig. 2b, c). These findings partly confirm our second hypothesis on animals rejecting biomass around the dung patches. Grazing avoidance by sheep in close vicinity to the dung patches was particularly distinct during the summer observation period, whereas plots containing dung patches were grazed to a similar height at the winter observation period. Hutchings et al. (1998) found increasing biting depth of sheep near dung with increasing age of the dung patch and initial avoidance was referred to odour of the dung. As opposed to this the vegetation stubble height left by grazing cattle only slightly changed for the longer winter observation period in comparison to the shorter summer observation period and was thus very high in the close vicinity to the dung patch (Fig. 2b). The difference in grazing selectivity between the two animal species is in line with findings by Cuchillo Hilario et al. (2017).

Avoided dung patches represent a substantial input of nutrients, which can increase soil fertility over a longer period (Aarons et al., 2009; Ma et al., 2013). As a consequence to the grazing avoidance and soil nutrient enrichment at the dung patches, Gillet et al. (2010) found seasonal changes in vegetation structure and composition around dung patches in oligotrophic and mesotrophic mountain pastures. Yoshitake et al. (2014) hypothesized the spatiotemporal restriction of dung effects to contribute to the heterogeneous pasture structure. Cattle can therefore create more patchy swards than sheep (Nolan et al., 2001), especially in the year following late grazing rotations. Moreover, the size of the rejected area around the dung patches may as well be affected by the animal stocking rate and hence the grazing intensity.

Unlike the plant biomass of the forage residue, the vegetation height measurement showed that cattle preferentially grazed at urine plots of grass-dominated swards in both observation periods. Apparent animal $\mathrm{N}$ and $\mathrm{K}$ intake in the following stocking period was also significantly higher at the urine plots than at the control and dung plots. The preference of recent urine patches by grazing animals was found in previous studies and was attributed to a higher quality and quantity of nutrients at urine compared to unaffected patches (Jaramillo \& Detling, 1992). Altogether, our results indicated that cattle and sheep grazing a low-input pasture did not differ 
in their biomass intake at the dung plots on the plot scale, however animal differences in grazing selectivity were observable in close vicinity to the dung patches.

\section{Conclusion}

The results of this study indicated that although the effects of excrement patches on plant parameters were detectable, the magnitude of effects was small in this low-input pasture and was hardly modified by animal species and sward composition differences. Even though excrement patches represented the main nutrient source at our experimental site, the effect on plant biomass production and nutrient concentration was smaller than in previous studies. The urine deposition of both animal species led to increases in plant biomass production and $\mathrm{N}$ and $\mathrm{K}$ uptake during both summer and winter observation periods. That an effect on plant biomass parameters could still be observed seven months after urine deposition may emphasize the importance of urine patches in low-input pastures. The mass of the forage residue in the presence of dung was increased for both cattle and sheep during both observation periods, but the small-scale vegetation height measurement showed a difference in avoidance of dung patches by the grazers. We therefore conclude that the variable vegetation response to nutrients influences the effect of excrement patches in this system.

\section{Acknowledgements}

This research project was funded by the Deutsche Forschungsgemeinschaft (DFG, reference number TO 895/1-1). We are grateful to Anne Vor, Philipp Langehenke, David Saal and the technical staff of our department for their help in the field and laboratory. Moreover we would like to thank Arne Oppermann, Knut Salzmann and all employees of the experimental farm of Relliehausen. 


\section{References}

Aarons SR, O’Connor CR, Hosseini HM, Gourley CJP (2009) Dung pads increase pasture production, soil nutrients and microbial biomass carbon in grazed dairy systems. Nutr Cycl Agroecosyst 84(1):81-92.

Auerswald K, Mayer F, Schnyder H (2010) Coupling of spatial and temporal pattern of cattle excreta patches on a low intensity pasture. Nutr Cycl Agroecosyst 88(2):275-288.

Bakker ES, Olff H, Boekhoff M, Gleichman JM, Berendse F (2004) Impact of herbivores on nitrogen cycling: contrasting effects of small and large species. Oecologia 138(1):91101.

Bélanger G, Rochette P, Chantigny M, Ziadi N, Angers D, Charbonneau É, Pellerin D, Liang C (2015) Nitrogen availability from dairy cow dung and urine applied to forage grasses in eastern Canada. Can J Plant Sci 95(1):55-65.

Cameron KC, Di HJ, Moir JL (2013) Nitrogen losses from the soil/plant system: A review. Ann Appl Biol 162(2):145-173.

Cuchillo Hilario M, Wrage-Mönnig N, Isselstein J (2017) Behavioral patterns of (co-)grazing cattle and sheep on swards differing in plant diversity. Appl Anim Behav Sci 191:1723.

Day TA, Detling JK (1990) Grassland patch dynamics and herbivore grazing preference following urine deposition. Ecology 71(1):180-188.

Decau ML, Simon JC, Jacquet A (2003) Fate of urine nitrogen in three soils throughout a grazing season. J Environ Qual 32(4):1405-1413.

Deenen P, Middelkoop N (1992) Effects of cattle dung and urine on nitrogen uptake and yield of perennial ryegrass. Neth J Agr Sci, 1992:469-482.

Dennis SJ, Moir JL, Cameron KC, Di HJ, Hennessy D, Richards KG (2011) Urine patch distribution under dairy grazing at three stocking rates in Ireland. Irish J Agr Food Res 50:149-160. 
Gillet F, Kohler F, Vandenberghe C, Buttler A (2010) Effect of dung deposition on small-scale patch structure and seasonal vegetation dynamics in mountain pastures. Agr Ecosyst Environ 135(1-2):34-41.

Haynes RJ, Williams PH (1993) Nutrient cycling and soil fertility in the grazed pasture ecosystem. Adv Agron 49:119-199.

Hirata M, Sugimoto Y, Ueno M (1988) Effects of cattle dung deposition on energy and matter flows in bahiagrass (Paspalum notatum Fluegge) pasture. 1. Changes in sward height and consumed herbage as related to rate of dung disappearance. J Jpn Grassl Sci 33(4):371-386.

Hoogendoorn CJ, Betteridge K, Costall DA, Ledgard SF (2010) Nitrogen concentration in the urine of cattle, sheep and deer grazing a common ryegrass/cocksfoot/white clover pasture. New Zeal J Agr Res 53(3):235-243.

Hutchings MR, Kyriazakis I, Anderson DH, Gordon IJ, Coop RL (1998) Behavioural strategies used by parasitized and non-parasitized sheep to avoid ingestion of gastro-intestinal nematodes associated with faeces. Anim Sci 67(01):97-106.

Janssens F, Peeters A, Tallowin J, Bakker JP, Bekker RM, Fillat F, Oomes M (1998) Relationship between soil chemical factors and grassland diversity. Plant Soil 202(1):69-78.

Jaramillo VJ, Detling JK (1992) Small-scale heterogeneity in a semi-arid north american grassland: II Cattle grazing of simulated urine patches. J Appl Ecol 29(1):9-13.

Jouven M, Agabriel J, Baumont R (2008) A model predicting the seasonal dynamics of intake and production for suckler cows and their calves fed indoors or at pasture. Anim Feed Sci Technol 143(1-4):256-279.

Kayser M, Müller J, Isselstein J (2007) Potassium leaching from cut grassland and from urine patches. Soil Use Manag 23(4):384-392.

Kirwan L, Lüscher A, Sebastià MT, Finn JA, Collins RP, Porqueddu C, Helgadottir A, Baadshaug OH, Brophy C, Coran C, Dalmannsdóttir S, Delgado I, Elgersma A, Fothergill M, Frankow-Lindberg BE, Golinski P, Grieu P, Gustavsson AM, Höglind M, Huguenin-Elie O, Iliadis C, Jørgensen M, Kadziuliene Z, Karyotis T, Lunnan T, Malengier M, Maltoni S, Meyer V, Nyfeller D, Nykanen-Kurki P, Parente J, Smit HJ, 
Thumm U, Connolly J (2007) Evenness drives consistent diversity effects in intensive grassland systems across 28 European sites. J Ecology 95(3):530-539.

Ledgard SF (2001) Nitrogen cycling in low input legume-based agriculture, with emphasis on legume/grass pastures. Plant Soil 228:43-59.

Lenth VR, Hervé M (2015) lsmeans: Least-Squares Means, R package version 2.17, Available at: http://CRAN.R-project.org/package=lsmeans.

Ma X, Ambus P, Wang S, wang Y, Wang C (2013) Priming of soil carbon decomposition in two Inner Mongolia grassland soils following sheep dung addition: a study using ${ }^{13} \mathrm{C}$ natural abundance approach. PloS one 8(11):e78578.

Ma X, Wang S, Jiang G, Haneklaus S, Schnug E, Nyren P (2007) Short-term effect of targeted placements of sheep excrement on grassland in inner Mongolia on soil and plant parameters. Comm Soil Sci Plant Anal 38(11-12):1589-1604.

Marsden KA, Jones DL, Chadwick DR (2016) Disentangling the effect of sheep urine patch size and nitrogen loading rate on cumulative $\mathrm{N}_{2} \mathrm{O}$ emissions. Anim Prod Sci 56(3):265.

Moir J, Cameron K, Di H (2016) Potential pasture nitrogen concentrations and uptake from autumn or spring applied cow urine and DCD under field conditions. Plants (Basel, Switzerland) 5(2).

Moir JL, Cameron KC, Di HJ, Fertsak U (2011) The spatial coverage of dairy cattle urine patches in an intensively grazed pasture system. J. Agric. Sci. 149(4):473-485.

Moir JL, Edwards GR, Berry LN (2013) Nitrogen uptake and leaching loss of thirteen temperate grass species under high N loading. Grass Forage Sci 68(2):313-325.

Moir JL, Malcolm BJ, Cameron KC, Di HJ (2012) The effect of dicyandiamide on pasture nitrate concentration, yield and $\mathrm{N}$ offtake under high $\mathrm{N}$ loading in winter and spring. Grass and Forage Sci 67(3):391-402.

Nolan T, Connolly J, Wachendorf M (2001) Mixed grazing and climatic determinants of white clover (Trifolium repens L.) content in a permanent pasture. Annals of Botany 88(4):713-724.

Orwin KH, Bertram JE, Clough TJ, Condron LM, Sherlock RR, O’Callaghan M (2009) Shortterm consequences of spatial heterogeneity in soil nitrogen concentrations caused by urine patches of different sizes. Appl Soil Ecol 42(3):271-278. 
Pinheiro J, Bates, D, Debroy, S, Sarkar, D, R Core Team (2015) nlme: Linear and Nonlinear Mixed Effects Models, R package version 3.1-120, Aivailable at: http://CRAN.Rproject.org/package $=$ nlme.

R Core Team (2015) R: A language and environment for statistical computing. R Foundation for Statistical Computing, Vienna, Austria: Available at: http://www.R-project.org/.

Rotz CA, Taube F, Russelle MP, Oenema J, Sanderson MA, Wachendorf M (2005) Wholefarm perspectives of nutrient flows in grassland agriculture. Crop Sci 45(6):21392159.

Saarijärvi K, Virkajärvi P (2009) Nitrogen dynamics of cattle dung and urine patches on intensively managed boreal pasture. J Agric Sci 147(04):479-491.

Seither M, Wrage-Mönnig N, Isselstein J (2014) Biomass production of Lolio-Cynosuretum grassland is not increased by plant-species richness. J. Plant Nutr. Soil Sci. 177(4):613-623.

Selbie DR, Buckthought LE, Shepherd MA (2015) The challenge of the urine patch for managing nitrogen in grazed pasture systems. Adv Agron 129:229-292.

Smith LA, White PC, Marion G, Hutchings MR (2009) Livestock grazing behavior and interversus intraspecific disease risk via the fecal-oral route. Behav Ecol 20(2):426-432.

Stewart K, Bourn N, Thomas JA (2001) An evaluation of three quick methods commonly used to assess sward height in ecology. J Appl Ecol 38(5):1148-1154.

Venables WN, Ripley BD (2002) Modern applied statistics with S-Plus. Springer, New York

Whitehead DC (2000) Nutrient elements in grassland: soil-plant-animal relationships. CAB International, Wallingford.

White-Leech R, Liu K, Sollenberger LE, Woodard KR, Interrante SM (2013a) Excreta deposition on grassland patches: I Forage harvested, nutritive value, and nitrogen recovery. Crop Sci 53(2):688-695.

White-Leech R, Liu K, Sollenberger LE, Woodard KR, Interrante SM (2013b) Excreta deposition on grassland patches: II. Spatial pattern and duration of forage responses. Crop Sci 53(2):1-8. 
Williams PH, Haynes RJ (1994) Comparison of initial wetting pattern, nutrient concentrations in soil solution and the fate of $15 \mathrm{~N}$-labelled urine in sheep and cattle urine patch areas of pasture soil. Plant Soil 162(1):49-59.

Williams PH, Haynes RJ (1995) Effect of sheep, deer and cattle dung on herbage production and soil nutrient content. Grass Forage Sci(50):263-271.

Yoshitake S, Soutome H, Koizumi H (2014) Deposition and decomposition of cattle dung and its impact on soil properties and plant growth in a cool-temperate pasture. Ecol Res 29(4):673-684. 
Chapter II:

Plant biomass production and soil nutrient availability following different excrement application times in a low-input pasture

Scheile T., Isselstein J., Tonn B.

Submitted to Soil Use and Management 


\begin{abstract}
Productivity of low-input pastures strongly depends on nutrient recycling via excrements of grazing animals. In our study excrements of cattle and sheep, collected from an adjacent rotational grazing system, were applied. Simulated urine and dung patches of cattle and sheep were created in spring on either grass-dominated or diverse permanent grassland swards. Additionally, cattle excrements were applied on diverse swards in summer and autumn. These treatments were compared to an untreated control and a fertilized control, representing the mean nutrient return by grazing animals. Aboveground plant biomass was sampled twice following excrement application in spring and summer and once following autumn. Belowground biomass and soil nutrients were sampled following the last aboveground biomass sampling. Soil was sampled separately below and around excrements. Aboveground biomass was only affected following spring application. The untreated control had a higher biomass on diverse than on grass-dominated swards. Dung patches decreased biomass at diverse swards. Cattle urine patches increased biomass at grass-dominated swards. Belowground biomass was not affected for any application time. The soil nutrient status indicated the greatest differences between treatments following spring application. Here the soil nutrient concentration was higher for cattle than for sheep excrements. Cattle urine patches significantly increased soil nitrate, ammonium and potassium concentration, cattle dung patches additionally increased phosphorus concentration. Sheep dung and urine only affected soil ammonium and nitrate concentration. Excrement application time and sward botanical composition affected the vegetation response. High soil nutrient concentration following spring application showed that nutrients were not fully used by the vegetation.
\end{abstract}

Keywords: Soil nutrients; Pasture; Heterogeneity; Excrements; Low-input 


\section{Introduction}

In extensively grazed semi-natural grassland systems nutrient cycling is primarily mediated by excrements of grazing animals (Rotz et al., 2005). Compared to high-input systems, these lowinput systems are mostly nitrogen (N)-limited. Excrements induce high nutrient loadings to a relatively small area and therefore are considered as 'hot spots' of intensive nutrient cycling (Haynes \& Williams, 1993). They are the main nutrient source for the pasture vegetation in these systems.

The nutrient partitioning between urine and dung causes different nutrient availabilities in urine and dung patches (Whitehead, 2000). Soil nutrient status changes rapidly within days following the deposition of urine (Shand et al., 2000) and over a longer period below dung patches (Aarons et al., 2009). The large input of immediately available $\mathrm{N}$ and potassium (K) with urine patches is far in excess of current plant requirements and can damage the vegetation root system below the patch (Shand et al., 2002). Parts of the urinary $\mathrm{N}$ may be lost due to volatilization as ammonia, but a higher proportion may be nitrified resulting in an accumulation of nitrate $\left(\mathrm{NO}_{3}{ }^{-}\right.$ ), which can be plant available, if not lost by leaching. The degradation of dung patches can increase soil phosphorus (P) and $\mathrm{K}$ content under the patch, as most of the $\mathrm{K}$ in dung is present as water soluble cations (Haynes \& Williams, 1993) and a high proportion of P is present in inorganic form (Whitehead, 2000; Aarons et al., 2009).

Plant biomass response to excrements can be influenced by a number of factors. Apart from possible nutrient losses following the excrement deposition (Cai \& Akiyama, 2016), grazing animal size (Bakker et al., 2004), pasture botanical composition and the time of excrement deposition (Bélanger et al., 2015; Moir et al., 2016) may be important factors.

Cattle and sheep represent two grazer species differing in size and nutrient return with their excrements (Haynes \& Williams, 1993). The size of excrement patches returned to the pasture can determine the nutrient availability at the patch scale (Orwin et al., 2009). More importantly, the animal diet alters nutrient concentration in the excrements and their partitioning between urine and dung (Selbie et al., 2015). The season of excrement application also alters the pasture production (Moir et al., 2011; Bélanger et al., 2015; Moir et al., 2016). On species-poor, grassdominated pastures, the high $\mathrm{N}$ input from excrements has been shown to strongly affect plant biomass production (White-Leech et al., 2013a, b). On grass-legume pastures, excrement 
patches can decrease the proportion of legumes and the amount of biologically fixed nitrogen, which offsets the effect of excrement-N input (Vinther, 1998).

So far, most studies on pasture response to simulated excrement patches were performed on intensively managed and fertilized pastures (Williams \& Haynes, 1994; Saarijärvi \& Virkajärvi, 2009; White-Leech et al., 2013a; Moir et al., 2016). Compared to low-input pastures, the contribution of excrement patches to the total pasture nutrient supply is less important in these systems. To get a better understanding of the importance of animal excrements for the plant biomass of diverse low-input pastures, the experimental design should, as far as possible, provide conditions close to a real grazing system, regarding excrement patch size, application rate and differing times of application. Due to seasonal dynamics of grassland biomass growth and different dynamics of nutrient release from urine and dung, observation of excrement effects should cover a whole grazing season.

Against this background, a field experiment was performed on a low-input semi-natural grassland using natural excrements of animals grazing at the same experimental site. This paper aimed to identify the effects of excrements on the pasture soil and vegetation under realistic conditions. Cattle and sheep excrements were applied on grassland swards of different botanical composition (diverse and grass-dominated) in spring, as the grass-dominated swards were expected to show a higher response to a high nutrient supply. Cattle excrements were applied in summer and autumn on diverse swards. Aboveground biomass was sampled in the subsequent growing season. Belowground biomass and soil nutrient status were assessed at the end of the experiment, to determine the medium-term pasture response to the excrements following a complete grazing season. This will give further information on excrement-mediated nutrient cycling in low-input pastures. 


\section{Material and Methods}

Overview

Timing of excrement application and biomass sampling in the experiment closely followed that of a grazing experiment established on immediately adjacent paddocks. This reference experiment was run with three consecutive stocking periods per year (spring, summer and autumn).

\section{Experimental site}

The experimental site is located in the Solling Uplands, Germany (51 $\left.46^{\prime} 47 \mathrm{~N}, 9^{\circ} 42^{\prime} 11 \mathrm{E}\right)$. Mean temperature and precipitation during the experiment are shown in Fig. 1. The soil type is a Vertic Cambisol (World Reference Base of Soils), the texture is clayey/silty loam. The initial botanical composition was a long-term permanent grassland corresponding to a moderately species rich Lolio-Cynosuretum. The experimental area was part of a prior mixed grazing experiment of cattle and sheep which ran from 2007-2011 (Seither et al., 2014). Thereafter the site was neither stocked nor fertilizer was applied and forage was cut twice per year (July and September) to a height of $7 \mathrm{~cm}$ and removed. 


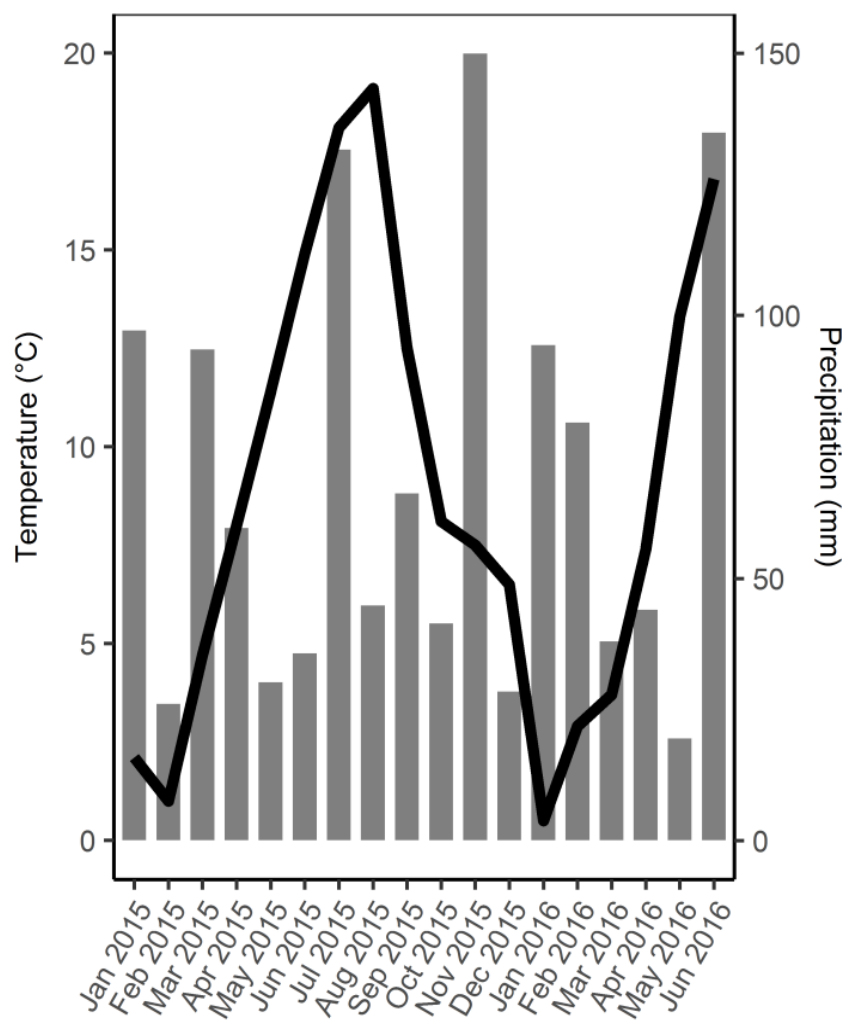

Figure 1 Monthly accumulated precipitation (mm) and mean temperature $\left({ }^{\circ} \mathrm{C}\right)$ for the experimental years 2015 and 2016. Bars indicate precipitation and line indicates temperature.

Experimental design and treatments

The study area consisted of 64 square plots with a size of $1.5^{*} 1.5 \mathrm{~m}^{2}$, split into 4 blocks. In autumn of 20146 plots per block were randomly chosen to manipulate the initial sward diversity by using herbicide against dicotyledonous plants (active components Fluroxypyr / Triclopyr), resulting in a low-diversity 'grass-dominated sward' and an untreated 'diverse sward'. In early spring 2015, the average contributions of plant functional groups to total biomass were visually estimated as $91 \%$ grasses, $8 \%$ herbs and $1 \%$ legumes at the grassdominated swards, and $63 \%$ grasses, $36 \%$ herbs and $1 \%$ legumes at the diverse swards.

Fresh urine and dung were collected directly before each of the three applications (Table 1) from cattle (adult, non-lactating suckler cows of the breed German Simmental) and sheep (adult, non-lactating Blackheaded sheep ewes) rotationally grazing on either grass-dominated or diverse pastures at the reference experiment. On the excrement collection days, 5 cattle and 30 sheep from each sward-type were brought into the barn in the morning to collect the 
excrements during voluntary urination and defecation. The urine was immediately stored in sealed, cooled containers until its application. Excrements were kept separate for animals grazing on grass-dominated or diverse swards and were later applied at the corresponding sward-types. The excrement nutrient concentrations were determined as shown in Table 2.

Excrement application rates and sizes were based on Haynes \& Williams (1993) and were 21 for cattle or 0.151 for sheep urine per plot. The urine was spread on the ground inside a metal ring with a diameter of $0.70 \mathrm{~m}$ for cattle and $0.42 \mathrm{~m}$ for sheep, which was placed in the centre of the plot to simulate the average surface area of a single urination. The dung plots received 2 $\mathrm{kg}$ of cattle or $0.1 \mathrm{~kg}$ of sheep dung (fresh weight), placed in the centre of the sampling area with a diameter of $0.3 \mathrm{~m}$ for cattle and $0.14 \mathrm{~m}$ for sheep. An 'untreated control' and a 'fertilized control' were established. The fertilized control received $5 \mathrm{~g} \mathrm{~N} \mathrm{~m}^{-2}$ (calcium ammonium nitrate), $0.75 \mathrm{~g} \mathrm{P} \mathrm{m}^{-2}$ (triple superphosphate) and $5.7 \mathrm{~g} \mathrm{~K} \mathrm{~m}^{-2}$ (potassium chloride) at each of the three application times. Application rates were calculated to represent mean nutrient return by grazing animals based on the mean nutrient return through excrements in the reference experiment during the previous year. The treatments cattle urine, cattle dung, sheep urine, sheep dung, unfertilized and fertilized control were realized in this study. All plots were sampled within a sampling area of $1 * 1 \mathrm{~m}^{2}$ for cattle and control and $0.5^{*} 0.5 \mathrm{~m}^{2}$ for sheep, respectively. 
Table 1 Overview over the course of the experiment, the experimental treatments and sampling times of aboveground, belowground biomass and soil.

\begin{tabular}{|c|c|c|c|c|c|}
\hline Application time & Treatment & Sward type & $\begin{array}{l}\text { Time of aboveground } \\
\text { biomass sampling }\end{array}$ & $\begin{array}{l}\text { Time of belowground } \\
\text { biomass sampling }\end{array}$ & Time of soil sampling \\
\hline $\begin{array}{l}\text { spring application } \\
(01-08 / 06 / 2015)\end{array}$ & $\begin{array}{l}\text { cattle urine or dung } \\
\text { sheep urine or dung } \\
\text { cattle urine or dung } \\
\text { sheep urine or dung } \\
\text { fertilized }\end{array}$ & $\begin{array}{c}\text { diverse } \\
\text { diverse } \\
\text { grass-dominated } \\
\text { grass-dominated } \\
\text { grass-dominated }\end{array}$ & $\begin{array}{l}\text { 13/07/2015(summer) and } \\
\text { 28/09/2015 (autumn) }\end{array}$ & 20-21/10/2015 (autumn) & $29-30 / 09 / 2015$ (autumn) \\
\hline $\begin{array}{l}\text { summer application } \\
(16 / 07 / 2015)\end{array}$ & $\begin{array}{l}\text { cattle urine or dung } \\
\text { fertilized }\end{array}$ & $\begin{array}{l}\text { diverse } \\
\text { diverse }\end{array}$ & $\begin{array}{c}28 / 09 / 2015 \text { (autumn) and } \\
07 / 06 / 2016 \text { (spring) }\end{array}$ & 20-21/06/2016 (spring) & 08/06/2016 (spring) \\
\hline $\begin{array}{l}\text { autumn application } \\
(30 / 09 / 2015)\end{array}$ & $\begin{array}{l}\text { cattle urine or dung } \\
\text { fertilized }\end{array}$ & $\begin{array}{l}\text { diverse } \\
\text { diverse }\end{array}$ & 07/06/2016 (spring) & 20-21/06/2016 (spring) & 08/06/2016 (spring) \\
\hline no application & $\begin{array}{l}\text { untreated } \\
\text { untreated }\end{array}$ & $\begin{array}{c}\text { diverse } \\
\text { grass-dominated }\end{array}$ & $\begin{array}{c}\text { 13/07/2015(summer), } \\
\text { 28/09/2015 (autumn) and } \\
\text { 07/06/2016 (spring) }\end{array}$ & $\begin{array}{l}\text { 20-21/10/2015 (autumn) } \\
20-21 / 06 / 2016 \text { (spring) }\end{array}$ & $\begin{array}{l}\text { 29-30/09/2015 (autumn) } \\
\text { 08/06/2016 (spring) }\end{array}$ \\
\hline
\end{tabular}

คे

Table 2 Nutrient concentrations of the cattle and sheep urine (fresh matter basis) and dung (dry matter basis) for the spring application on grass-dominated and diverse swards. Characteristics of the excrements for the summer and autumn application on diverse swards. ND not determined.

\begin{tabular}{|c|c|c|c|c|c|c|c|c|}
\hline \multirow{2}{*}{ Animal } & \multirow{2}{*}{ Application time } & \multirow{2}{*}{ Sward type } & \multicolumn{3}{|c|}{ Urine } & \multicolumn{3}{|c|}{ Dung } \\
\hline & & & $\mathrm{N}\left(\mathrm{g} \mathrm{l}^{-1}\right)$ & $\mathrm{P}\left(\mathrm{g} \mathrm{l}^{-1}\right)$ & $\mathrm{K}\left(\mathrm{g} \mathrm{l}^{-1}\right)$ & $\mathrm{N}\left(\mathrm{g} \mathrm{kg}^{-1}\right)$ & $\mathrm{P}\left(\mathrm{g} \mathrm{kg}^{-1}\right)$ & $\mathrm{K}\left(\mathrm{g} \mathrm{kg}^{-1}\right)$ \\
\hline cattle & & diverse & 4.7 & 0.011 & 1.84 & 23.6 & 10.7 & 7.8 \\
\hline cattle & & grass-dominated & ND & ND & ND & 21.4 & 9.4 & 14.4 \\
\hline sheep & spring $2015(01-08 / 06)$ & diverse & 1.6 & 0.002 & 7.40 & 27.3 & 12.4 & 18.9 \\
\hline sheep & & grass-dominated & 4.1 & 0.008 & 8.23 & 23.5 & 8.4 & 22.9 \\
\hline cattle & summer $2015(16 / 07)$ & diverse & 1.2 & 0.003 & 14.33 & 21.1 & 8.8 & 9.7 \\
\hline cattle & autumn $2015(30 / 09)$ & diverse & 1.4 & 0.003 & 4.07 & 20.3 & 9.2 & 12.9 \\
\hline
\end{tabular}


Aboveground plant biomass was sampled in the two subsequent grazing rotations following application in spring and summer and in one rotation following excrement application in autumn. One half of each sampling area was randomly chosen at the first sampling date (Table 1) and the plant biomass was cut to a vegetation height of $2 \mathrm{~cm}$ using an electric scissors. The other half was sampled at the second sampling date. For the control plots one quarter of the sampling area was randomly chosen and in the subsequent sampling dates the other quarters were sampled. Following each sampling, the plant biomass of the unsampled parts of the sampling area and of the areas that received treatments at subsequent application times were cut to a vegetation height of $7 \mathrm{~cm}$ and plant biomass was removed. Sampled plant biomass was dried to constant weight for 48 hours at $60{ }^{\circ} \mathrm{C}$ to determine the dry matter (DM). For sampling areas with spring or summer application, DM of both sampling dates was summed up for further calculations to represent the accumulated biomass (Table 1).

Ten soil cores (diameter $1.5 \mathrm{~cm}$ ) were collected in each plot from 0-10 cm depth either below the dung and urine patches ('centre') or distributed over the rest of the sampling area ('edge') following the last plant biomass sampling. Dung was removed before soil sampling below dung patches. The soil samples were analysed for their ammonium $\left(\mathrm{NH}_{4}{ }^{+}\right)$and nitrate $\left(\mathrm{NO}_{3}{ }^{-}\right)$ concentration following extraction with $\mathrm{KCl}$. Phosphorus $(\mathrm{P})$ and potassium $(\mathrm{K})$ concentration were analysed after extraction with calcium acetate lactate, using a continuous flow analyser (Seal Analytical, Norderstedt).

Belowground biomass was sampled shortly after the soil sampling. Per plot, 10 soil cores with a diameter of $1.64 \mathrm{~cm}$ were taken to a depth of $20 \mathrm{~cm}$. The number of soil cores taken below the excrement patches corresponded to the proportion of the sampling area covered by the excrement patch. Roots were washed and dried to constant weight for $24 \mathrm{~h}$ at $30{ }^{\circ} \mathrm{C}$ to determine belowground biomass DM. 
The statistical analysis was done using the program $\mathrm{R}$ version 3.2.0 (R Core Team, 2015). Influence of treatment and sward on the response variables were examined using linear mixed effects (LME) models and the package nlme (Pinheiro et al., 2015). For spring application, LME models had the fixed effects treatment (cattle urine, cattle dung, sheep urine, sheep dung and untreated and fertilized control) and sward type (grass-dominated and diverse) as well as their interactions. For summer and autumn applications, treatment (cattle urine, cattle dung, untreated and fertilized control) was the only fixed effect. All models considered the replicate blocks as random effects. Homogeneity of variance and normal distribution were checked for all residuals and a boxcox function was used to determine an appropriate transformation using the MASS package (Venables \& Ripley, 2002). The initial models were simplified by removing non-significant interactions or factors, if this led to a lower value of second-order Akaike Information Criterion (AICc) of the resulting model. Pair-wise comparison of means was performed in case of significant fixed effects using the LSD test implemented in the package lsmeans (Lenth \& Hervé, 2015). 


\section{Results}

Above- and belowground biomass

Aboveground biomass was significantly affected by excrements following application in spring (Table 3). Here it showed a significant treatment*sward interaction. On grass-dominated swards the plots receiving fertilizer or excrements tended to have a higher accumulated biomass than the untreated control. Accumulated aboveground biomass was 59\% higher on cattle urine patches in comparison to the unfertilized control, while the values at the other excrement patches did not differ significantly from the untreated control. On diverse swards the accumulated aboveground biomass following the cattle urine application was $16 \%$ higher than at the untreated control plots, but this difference was not significant. The application of cattle and sheep dung led to a $39 \%$ and $33 \%$ lower accumulated aboveground biomass compared to the untreated control. Furthermore, the accumulated biomass of untreated control plots was significantly higher $(33 \%)$ on diverse than on grass-dominated swards. No significant treatment effects on the belowground biomass were measured for any application time.

\section{Soil nutrient concentration}

Following excrement application in spring, the $\mathrm{NH}_{4}{ }^{+}$concentration in the centre of cattle dung patches was significantly higher than in the other treatments (Table 4). The edge sampling area of all excrement patches had a significantly higher $\mathrm{NH}_{4}{ }^{+}$concentration than the untreated control plots. Treatment application in summer only increased the $\mathrm{NH}_{4}{ }^{+}$content of the fertilized control. Here it was significantly higher than for cattle excrements at the edge sampling area. Following the autumn application, the $\mathrm{NH}_{4}{ }^{+}$concentration of the edge sampling area was significantly higher at cattle urine and fertilized control plots than at the cattle dung plots.

The $\mathrm{NO}_{3}{ }^{-}$concentration in the centre and the edge sampling area was only significantly affected by excrements following spring and summer application. Following spring application, the $\mathrm{NO}_{3}{ }^{-}$concentration in the centre sampling area was significantly higher at plots receiving animal excrements than at the untreated control plots. The $\mathrm{NO}_{3}{ }^{-}$concentration in the centre 
sampling area was significantly higher on grass-dominated swards than on diverse swards. For the summer application the $\mathrm{NO}_{3}{ }^{-}$in the centre sampling area was significantly higher for both control plots compared to the cattle dung plots. Additionally the $\mathrm{NO}_{3}{ }^{-}$concentration at the edge sampling area was significantly lower for both cattle excrements in comparison to the fertilized control plots.

Table 3 Mean values ( \pm standard error) and results of statistical analysis ( $P$ values) for above- and belowground plant biomass. Plant biomass dry matter (DM) for spring and summer application represents two consecutive cuts (accumulated biomass), plant biomass DM for autumn application only one cut. Means with different letters indicate significant differences between treatments within application date (linear mixed effect models with Tukey LSD test at $\mathrm{P}<0.05)$.

\begin{tabular}{|c|c|c|c|c|}
\hline \multirow{2}{*}{ Application time } & \multirow{2}{*}{ Treatment } & \multicolumn{2}{|c|}{ Aboveground biomass DM $\left(\mathrm{g} \mathrm{m}^{-2}\right)$} & \multirow{2}{*}{$\begin{array}{c}\text { Belowground biomass } \\
\text { DM }\left(\mathrm{g} \mathrm{m}^{-2}\right)\end{array}$} \\
\hline & & Diverse & Grass-dominated & \\
\hline \multirow[t]{6}{*}{ spring } & sheep urine & $399 \pm 19^{\text {bcde }}$ & $390 \pm 61^{\mathrm{bcd}}$ & $155 \pm 50$ \\
\hline & sheep dung & $315 \pm 45^{\mathrm{ab}}$ & $339 \pm 28^{\mathrm{abc}}$ & $128 \pm 35$ \\
\hline & cattle urine & $550 \pm 41^{\mathrm{e}}$ & $506 \pm 84^{\mathrm{de}}$ & $258 \pm 101$ \\
\hline & cattle dung & $287 \pm 53^{\mathrm{a}}$ & $349 \pm 19^{\mathrm{abc}}$ & $142 \pm 27$ \\
\hline & untreated & $473 \pm 35^{\mathrm{de}}$ & $319 \pm 19^{\mathrm{ab}}$ & $161 \pm 30$ \\
\hline & fertilized & $411 \pm 47^{\text {bcde }}$ & $441 \pm 74^{\text {cde }}$ & $211 \pm 44$ \\
\hline \multicolumn{5}{|l|}{$P$ value } \\
\hline treatment & & \multicolumn{2}{|c|}{$<0.001$} & n.s. \\
\hline sward & & \multirow{2}{*}{\multicolumn{2}{|c|}{$\begin{array}{c}\text { n.s. } \\
<0.001\end{array}$}} & n.s. \\
\hline treatment*sward & & & & n.s. \\
\hline \multirow[t]{4}{*}{ summer } & cattle urine & $565 \pm 93$ & - & $113 \pm 18$ \\
\hline & cattle dung & $405 \pm 40$ & - & $128 \pm 33$ \\
\hline & untreated & $513 \pm 52$ & - & $157 \pm 48$ \\
\hline & fertilized & $543 \pm 53$ & - & $207 \pm 39$ \\
\hline \multicolumn{5}{|l|}{$P$ value } \\
\hline treatment & & \multicolumn{2}{|c|}{ n.s. } & n.s. \\
\hline \multirow[t]{4}{*}{ autumn } & cattle urine & $332 \pm 36$ & - & $216 \pm 18$ \\
\hline & cattle dung & $331 \pm 33$ & - & $165 \pm 37$ \\
\hline & untreated & $266 \pm 43$ & - & $157 \pm 48$ \\
\hline & fertilized & $332 \pm 47$ & - & $207 \pm 39$ \\
\hline \multicolumn{5}{|l|}{$P$ value } \\
\hline treatment & & & & n.s. \\
\hline
\end{tabular}


In soil samples taken following spring application, the highest extractable $\mathrm{P}$ concentration in the centre of the sampling area was found at dung patches. Soil P concentration remained unaffected following the summer and autumn application. Following spring application the extractable K concentration in the centre sampling area was significantly highest for dung and urine patches of cattle. The $\mathrm{K}$ concentration in the centre of the sampling area was also significantly higher on sheep urine than sheep dung plots. Moreover, there was a difference between the sward types, with higher $\mathrm{K}$ concentration on grass-dominated than on diverse swards, but this was only found for the centre sampling area. Following summer application of excrements, the cattle urine patches had a significantly higher $\mathrm{K}$ concentration in the centre sampling area than the untreated control. The cattle excrement application in autumn had no effect on the extractable K concentration. 


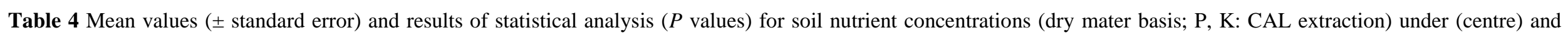

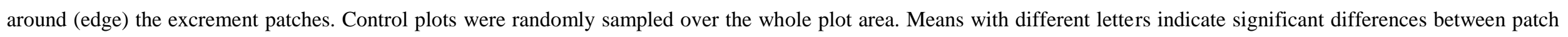
types within either centre or edge (linear mixed effect models with Tukey LSD test at $P<0.05$ ).

\begin{tabular}{|c|c|c|c|c|c|c|c|c|c|}
\hline \multirow{2}{*}{ Application time } & \multirow{2}{*}{ Treatment } & \multicolumn{2}{|c|}{$\mathrm{NH}_{4}^{+}\left(\mathrm{mg} \mathrm{kg}^{-1}\right)$} & \multicolumn{2}{|c|}{$\mathrm{NO}_{3}^{-}\left(\mathrm{mg} \mathrm{kg}^{-1}\right)$} & \multicolumn{2}{|c|}{$\mathrm{P}\left(\mathrm{mg} \mathrm{kg}^{-1}\right)$} & \multicolumn{2}{|c|}{$\mathrm{K}\left(\mathrm{mg} \mathrm{kg}^{-1}\right)$} \\
\hline & & Centre & Edge & Centre & Edge & Centre & Edge & Centre & Edge \\
\hline \multirow[t]{6}{*}{ spring } & sheep urine & $2.9 \pm 0.3^{\mathrm{a}}$ & $3.0 \pm 0.4^{\mathrm{c}}$ & $2.4 \pm 0.7^{\mathrm{bc}}$ & $2.0 \pm 0.3^{\mathrm{b}}$ & $69.9 \pm 8.3^{\mathrm{a}}$ & $72.1 \pm 6.7$ & $271.5 \pm 34.1^{\mathrm{b}}$ & $250.5 \pm 13.0$ \\
\hline & sheep dung & $3.1 \pm 0.6^{\mathrm{a}}$ & $2.9 \pm 0.4^{b c}$ & $1.9 \pm 0.4^{\mathrm{b}}$ & $2.0 \pm 0.2^{b}$ & $59.6 \pm 8.0^{\mathrm{a}}$ & $56.1 \pm 5.5$ & $215.5 \pm 17.3^{\mathrm{a}}$ & $234.3 \pm 22.6$ \\
\hline & cattle urine & $2.9 \pm 0.4^{\mathrm{a}}$ & $2.6 \pm 0.3^{b c}$ & $5.1 \pm 2.9^{c}$ & $3.8 \pm 1.9^{\mathrm{b}}$ & $64.0 \pm 7.5^{\mathrm{a}}$ & $68.3 \pm 4.6$ & $399.8 \pm 72.7^{\mathrm{c}}$ & $272.6 \pm 26.7$ \\
\hline & cattle dung & $3.3 \pm 0.7^{b}$ & $2.7 \pm 0.3^{b c}$ & $5.5 \pm 4.0^{\mathrm{c}}$ & $2.9 \pm 1.4^{\mathrm{b}}$ & $100.8 \pm 9.5^{\mathrm{b}}$ & $72.4 \pm 5.5$ & $371.9 \pm 36.2^{c}$ & $267.6 \pm 22.3$ \\
\hline & untreated & $2.1 \pm 0.1^{\mathrm{a}}$ & $2.1 \pm 0.1^{\mathrm{a}}$ & $1.3 \pm 0.1^{\mathrm{a}}$ & $1.3 \pm 0.1^{\mathrm{a}}$ & $66.2 \pm 9.1^{\mathrm{a}}$ & $66.2 \pm 9.1$ & $231.0 \pm 26.4^{\mathrm{ab}}$ & $231.0 \pm 26.4$ \\
\hline & fertilized & $2.3 \pm 0.3^{\mathrm{a}}$ & $2.3 \pm 0.3^{\mathrm{ab}}$ & $1.9 \pm 0.4^{b}$ & $1.9 \pm 0.4^{b}$ & $67.0 \pm 13.5^{\mathrm{a}}$ & $67.0 \pm 13.5$ & $245.1 \pm 30.8^{\mathrm{ab}}$ & $245.1 \pm 30.8$ \\
\hline \multicolumn{10}{|l|}{$P$ value } \\
\hline treatment & & 0.0017 & 0.007 & $<0.001$ & 0.0012 & 0.0016 & n.s. & $<0.001$ & n.s \\
\hline sward & & n.s. & n.s. & 0.0329 & n.s. & n.s. & n.s. & $<0.001$ & n.s. \\
\hline treatment*sward & & n.s. & n.s. & n.s. & n.s. & n.s. & n.s. & n.s. & n.s. \\
\hline \multirow[t]{4}{*}{ summer } & cattle urine & $3.8 \pm 0.3$ & $3.5 \pm 0.2^{\mathrm{a}}$ & $1.8 \pm 0.6^{\mathrm{ab}}$ & $1.5 \pm 0.3^{\mathrm{ab}}$ & $64.1 \pm 10.2$ & $71.6 \pm 10.9$ & $305.6 \pm 17.7^{\mathrm{b}}$ & $284.4 \pm 25.9$ \\
\hline & cattle dung & $3.6 \pm 0.4$ & $3.4 \pm 0.1^{\mathrm{a}}$ & $1.4 \pm 0.2^{\mathrm{a}}$ & $1.2 \pm 0.3^{\mathrm{a}}$ & $70.7 \pm 12.0$ & $69.4 \pm 6.6$ & $249.0 \pm 24.8^{\mathrm{a}}$ & $255.3 \pm 10.8$ \\
\hline & untreated & $3.8 \pm 0.1$ & $3.8 \pm 0.1^{\mathrm{ab}}$ & $2.2 \pm 0.3^{\mathrm{b}}$ & $2.2 \pm 0.3^{\mathrm{bc}}$ & $57.3 \pm 8.5$ & $57.3 \pm 8.5$ & $212.0 \pm 19.2^{\mathrm{a}}$ & $212.0 \pm 19.2$ \\
\hline & fertilized & $5.0 \pm 0.7$ & $5.0 \pm 0.7^{b}$ & $2.6 \pm 0.3^{b}$ & $2.6 \pm 0.3^{c}$ & $69.4 \pm 8.5$ & $69.4 \pm 8.5$ & $252.3 \pm 27.0^{\mathrm{ab}}$ & $252.3 \pm 27.5$ \\
\hline \multicolumn{10}{|l|}{$P$ value } \\
\hline treatment & & n.s. & 0.0326 & 0.0028 & 0.0366 & n.s. & n.s. & 0.003 & n.s. \\
\hline \multirow[t]{4}{*}{ Autumn } & cattle urine & $3.8 \pm 0.4$ & $4.2 \pm 0.6^{\mathrm{b}}$ & $2.5 \pm 0.7$ & $2.0 \pm 0.4$ & $64.6 \pm 11.0$ & $69.8 \pm 11.9$ & $296.7 \pm 31.1$ & $241.9 \pm 18.5$ \\
\hline & cattle dung & $4.0 \pm 0.4$ & $3.3 \pm 0.2^{\mathrm{a}}$ & $2.2 \pm 0.4$ & $1.4 \pm 0.3$ & $155.3 \pm 54.2$ & $76.7 \pm 3.5$ & $300.8 \pm 42.8$ & $223.9 \pm 18.0$ \\
\hline & untreated & $3.8 \pm 0.1$ & $3.8 \pm 0.1^{\mathrm{ab}}$ & $2.2 \pm 0.3$ & $2.2 \pm 0.3$ & $57.3 \pm 8.5$ & $57.3 \pm 8.5$ & $212.0 \pm 19.2$ & $212.0 \pm 19.2$ \\
\hline & fertilized & $5.0 \pm 0.7$ & $5.0 \pm 0.7^{\mathrm{b}}$ & $2.6 \pm 0.3$ & $2.6 \pm 0.3$ & $69.4 \pm 8.5$ & $69.4 \pm 8.5$ & $252.3 \pm 27.0$ & $252.3 \pm 27.0$ \\
\hline
\end{tabular}

$P$ value

treatment

n.s. $\quad 0.0371$

n.s.

n.s.

n.s.

n.s.

n.s.

n.s 


\section{Discussion}

Nutrient concentration of excrements

Nutrient concentration of excrements applied in our study showed great heterogeneity for the single application times (Table 2). They were distinctly lower than those reported by others (Haynes \& Williams, 1993; Williams \& Haynes, 1995; Shand et al., 2002), which could be attributed to the low-input management of the reference experiment (Haynes \& Williams, 1993). Especially the urine $\mathrm{N}$ and $\mathrm{K}$ concentrations were widely ranging for single animal species and excrement application times. Additionally, nutrient concentration of cattle excrements tended to be lower for summer and autumn than for spring application. The excrement nutrient concentration of grazing herbivores varies depending on the quality of ingested forage (Whitehead, 1995). Urine $\mathrm{N}$ was previously reported to vary between and within days and within animals of the same species (Hoogendoorn et al., 2010). Thus under realistic grazing conditions both grazing management system and animal specific differences resulted in heterogeneous excrement nutrient concentrations, which consequently altered the amount of nutrients applied in our study.

\section{Above- and belowground biomass}

In the system used, treatments represented the main nutrient source for pasture vegetation growth, which should have led to high biomass response to the nutrients applied. However, aboveground biomass was only significantly affected following spring application of excrements with the highest biomass found at the cattle urine plots, which lasted over four months following application. Although replications of each treatment received the same amount of nutrients, the high standard error of aboveground biomass indicated a great heterogeneity. It appeared that nutrient application led to a higher increase of aboveground biomass at grass-dominated than at diverse swards. But even at the grass-dominated swards the effect of cattle urine on aboveground biomass was distinctly lower than reported by others for 
intensively managed pastures (Saarijärvi \& Virkajärvi, 2009; White-Leech et al., 2013a). This implied a small response of aboveground biomass to the nutrients in our study.

Dung patches of both cattle and sheep had markedly negative effects on aboveground biomass at diverse swards. This negative effect was stronger following spring than for the later applications. For dung patches an initial negative effect on pasture vegetation, which can be followed by an increased production of vegetation surrounding the patches, was reported (MacDiarmid \& Watkin, 1971; Aarons et al., 2009). Smothering of incompletely decomposed cattle dung patches could have had a great impact on vegetation (MacDiarmid \& Watkin, 1971) in spring. Other than reported (Williams \& Haynes, 1995; Ma et al., 2007) our findings imply a negative effect of sheep dung patches over four months on diverse swards.

Our results showed a very heterogeneous nutrient concentration of excrements and that the naturally developed diverse pasture influences the fertilizing effect of excrements under real grazing conditions. They moreover implied that the rotational grazing system induces a shift of nutrient availability within the grazing season, which does not necessarily overlap with times of high plant nutrient demand. However, other factors like warm conditions on the day of application in summer $\left(20.1^{\circ} \mathrm{C}\right)$ may have increased ammonia volatilization losses (Bolan $e t$ $a l ., 2004)$ and nutrient leaching losses following autumn application, due to low plant nutrient demand (Saarijärvi \& Virkajärvi, 2009), could have lowered the excrement effect on aboveground biomass. Against this, Bélanger et al. (2015) reported that cattle excrement application later in the year can increase forage production in the following year. But like other studies reporting high effects of excrements on aboveground biomass, their experiment was performed on recently resown pastures. As opposed to this, the grassland sward in our study developed naturally and thus was very old, which could have altered the pasture response to the nutrients. This assumption may be supported by the difference in production of the untreated grass-dominated and diverse control plots. In contrast to the results of Seither et al. (2014), untreated control had a higher forage production at diverse than at grass-dominated swards, whereas the grass-dominated swards showed a higher response to the nutrient supply. Furthermore the spatially homogeneous nutrient return of the fertilized control led to a differing pasture production of the sward-types.

No response of belowground biomass to the excrement application was found at the end of the respective grazing periods. Belowground biomass responded heterogeneously to the nutrient input at the plots for all application times. Apart from a possible root damage following 
application of nutrient rich urine patches (Shand et al., 2000; Shand et al., 2002), the nutrient addition to the $\mathrm{N}$ limited experimental site (Seither et al., 2014) should have caused root proliferation (Hodge, 2004). The results may imply that excrements do not affect belowground biomass in the low-input system over a long period.

\section{Soil nutrient concentration}

The soil nutrient sampling at the experimental plots was intended to give further information on the spatial pattern of the soil nutrient status at the end of the simulated grazing seasons and thus on the nutrient availability for subsequent plant growth. Treatments differed most strongly following spring application, where soil nutrient status differed distinctly between animal species and excrement patches. The $\mathrm{NO}_{3}{ }^{-}$concentration in the centre sampling area and the $\mathrm{NH}_{4}{ }^{+}$and $\mathrm{NO}_{3}{ }^{-}$concentrations in both sampling areas of dung patches were significantly higher than at the untreated control. Rapid hydrolysis of urea in urine and subsequent nitrification (Williams \& Haynes, 1994) promoted the $\mathrm{NO}_{3}{ }^{-}$concentration. However, high proportions of organically bound $\mathrm{N}$ in dung (White-Leech et al., 2013a) led to a continuous contribution of $\mathrm{N}$ to the soil, consequently increasing soil $\mathrm{NH}_{4}{ }^{+}$concentration (Castillo et al., 2010). The $\mathrm{NO}_{3}{ }^{-}$ concentrations were higher at cattle than at sheep urine patches. Due to the higher application rates and larger area covered by cattle, their patches retain $\mathrm{N}$ for a longer period than the smaller sheep urine patches (Orwin et al., 2009), which affects the further flow depth and thus $\mathrm{N}$ conversion in the soil (Williams \& Haynes, 1994). All excrement patch types showed significantly higher $\mathrm{NH}_{4}{ }^{+}$concentration at the edge sampling area than the untreated control, suggesting a possible nutrient leaching to the area surrounding the excrement patches.

The high urine application rates of cattle additionally increased the extractable $\mathrm{K}$ found following spring and summer application. Urine $\mathrm{K}$ can be adsorbed by soil exchange sites (Williams et al., 1990), as soil and plant are the main sinks for urine K (Kayser et al., 2007). Furthermore the $\mathrm{NH}_{4}{ }^{+}$, extractable $\mathrm{P}$ and $\mathrm{K}$ soil concentration were significantly higher in the centre of cattle than sheep dung patches, which may be partly attributed to the difference in decomposition (Aarons et al., 2004), but was also affected by the generally higher dung application rates of cattle (Haynes \& Williams, 1993). Additionally, the high content of soluble $\mathrm{K}$ in dung (Williams \& Haynes, 1995; Aarons et al., 2004) led to a significantly higher 
extractable $\mathrm{K}$ under cattle dung patches in comparison to both control plots. The low soil nutrient concentrations following summer application could be caused by several heavy rain showers within the first 10 days following the application (in total $47.6 \mathrm{~mm}$ ). This could have increased nutrient losses from urine and dung (McDowell, 2006; Saarijärvi \& Virkajärvi, 2009). Even following a whole grazing period, cattle and sheep excrements differed significantly in their effect on soil nutrient status. However, soil nutrient concentration was mostly significantly higher at the excrements and fertilized control than at the untreated control, indicating that pasture vegetation did not fully use the additional plant-available nutrients. Consequently grazing herbivores can contribute to increasing soil spatial heterogeneity in diverse grasslands (Liu et al., 2016), which may, in the longer term, lead to more heterogeneous swards (Gillet et al., 2010).

\section{Conclusion}

The aim of this experiment was to examine the relevance of excrement nutrients under conditions close to a real low-input grazing system. It showed that excrement nutrient concentration, plant biomass production and soil nutrient status of the pasture had a great variability. Even though representing the main nutrient source, the application of excrements did not always concur with plant nutrient demand and thus did not affect plant biomass for all application times. It can be concluded that the mid-term effect of grazing animal excrements at the patch scale mainly depended on the application time. Even a simulated uniform grazing and nutrient return, as represented by the fertilized control, had no consistent effect on the pasture and soil nutrient status. When upscaling this small-scale heterogeneity to the paddock, cattle excrements could lead to a higher spatial heterogeneity in soil nutrient status and consequently in plant biomass production in low-input pastures than sheep excrements (Liu et al., 2016), due to their more coarse nutrient return. Examination of nutrient losses at the excrement patches and an exact acquisition of plant species at the pasture would give further information on the heterogeneous forage response and soil nutrient concentration. 


\section{References}

Aarons, S.R., O'Connor, C.R. \& Gourley, C.J.P. 2004. Dung decomposition in temperate dairy pastures. I. Changes in soil chemical properties. Australian Journal of Soil Research, $42,107-114$.

Aarons, S.R., O’Connor, C.R., Hosseini, H.M. \& Gourley, C.J.P. 2009. Dung pads increase pasture production, soil nutrients and microbial biomass carbon in grazed dairy systems. Nutrient Cycling in Agroecosystems, 84, 81-92.

Bakker, E.S., Olff, H., Boekhoff, M., Gleichman, J.M. \& Berendse, F. 2004. Impact of herbivores on nitrogen cycling: Contrasting effects of small and large species. Oecologia, 138, 91-101.

Bélanger, G., Rochette, P., Chantigny, M., Ziadi, N., Angers, D., Charbonneau, É., Pellerin, D. \& Liang, C. 2015. Nitrogen availability from dairy cow dung and urine applied to forage grasses in eastern Canada. Canadian Journal of Plant Science, 95, 55-65.

Bolan, N.S., Saggar, S., Luo, J., Bhandral, R. \& Singh, J. 2004. Gaseous emissions of nitrogen from grazed pastures: processes, measurements and modelling, environmental implications, and mitigation. Advances in Agronomy, 84, 37-120.

Cai, Y. \& Akiyama, H. 2016. Nitrogen loss factors of nitrogen trace gas emissions and leaching from excreta patches in grassland ecosystems: A summary of available data. The Science of the Total Environment, 572, 185-195.

Castillo, M.S., Sollenberger, L.E., Vendramini, J.M., Woodard, K.R., Gilmour, J.T., O'Connor, G.A., Newman, Y.C., Silveira, M.L. \& Sartain, J.B. 2010. Municipal biosolids as an alternative nutrient source for bioenergy crops: II. Decomposition and organic nitrogen mineralization. Agronomy Journal, 102, 1314-1320.

Gillet, F., Kohler, F., Vandenberghe, C. \& Buttler, A. 2010. Effect of dung deposition on smallscale patch structure and seasonal vegetation dynamics in mountain pastures. Agriculture, Ecosystems \& Environment, 135, 34-41.

Haynes, R.J. \& Williams, P.H. 1993. Nutrient cycling and soil fertility in the grazed pasture ecosystem. Advances in Agronomy, 49, 119-199. 
Hodge, A. 2004. The plastic plant: Root responses to heterogeneous supplies of nutrients. New Phytologist, 162, 9-24.

Hoogendoorn, C.J., Betteridge, K., Costall, D.A. \& Ledgard, S.F. 2010. Nitrogen concentration in the urine of cattle, sheep and deer grazing a common ryegrass/cocksfoot/white clover pasture. New Zealand Journal of Agricultural Research, 53, 235-243.

Kayser, M., Müller, J. \& Isselstein, J. 2007. Potassium leaching from cut grassland and from urine patches. Soil Use and Management, 23, 384-392.

Lenth, V.R. \& Hervé, M. 2015. 1smeans: Least-Squares Means, R package version 2.17, Available at: http://CRAN.R-project.org/package=lsmeans.

Liu, C., Song, X., Wang, L., Wang, D., Zhou, X., Liu, J., Zhao, X., Li, J., Lin, H. \& Wan, S. 2016. Effects of grazing on soil nitrogen spatial heterogeneity depend on herbivore assemblage and pre-grazing plant diversity. Journal of Applied Ecology, 53, 242-250.

Ma, X., Wang, S., Jiang, G., Haneklaus, S., Schnug, E. \& Nyren, P. 2007. Short-term effect of targeted placements of sheep excrement on grassland in Inner Mongolia on soil and plant parameters. Communications in Soil Science and Plant Analysis, 38, 1589-1604.

MacDiarmid, B.N. \& Watkin, B.R. 1971. The cattle dung patch. 1. Effect of dung patches on yield and botanical composition of surrounding and underlying pasture. Journal of the British Grassland Society, 26, 239-245.

McDowell, R.W. 2006. Contaminant losses in overland flow from cattle, deer and sheep dung. Water, Air, and Soil Pollution, 174, 211-222.

Moir, J.L., Cameron, K.C., Di, H.J. \& Fertsak, U. 2011. The spatial coverage of dairy cattle urine patches in an intensively grazed pasture system. The Journal of Agricultural Science, 149, 473-485.

Moir, J., Cameron, K. \& Di, H. 2016. Potential pasture nitrogen concentrations and uptake from autumn or spring applied cow urine and DCD under field conditions. Plants, 5.

Orwin, K.H., Bertram, J.E., Clough, T.J., Condron, L.M., Sherlock, R.R. \& O’Callaghan, M. 2009. Short-term consequences of spatial heterogeneity in soil nitrogen concentrations caused by urine patches of different sizes. Applied Soil Ecology, 42, 271-278. 
Pinheiro, J., Bates, D, Debroy, S, Sarkar, D \& R Core Team. 2015. nlme: Linear and nonlinear mixed effects models, R package version 3.1-120, Aivailable at: http://CRAN.Rproject.org/package=nlme.

R Core Team. 2015. R: A language and environment for statistical computing. R Foundation for Statistical Computing, Vienna, Austria: Available at: http://www.R-project.org/.

Rotz, C.A., Taube, F., Russelle, M.P., Oenema, J., Sanderson, M.A. \& Wachendorf, M. 2005. Whole-farm perspectives of nutrient flows in grassland agriculture. Crop Science, 45 , 2139-2159.

Saarijärvi, K. \& Virkajärvi, P. 2009. Nitrogen dynamics of cattle dung and urine patches on intensively managed boreal pasture. The Journal of Agricultural Science, 147, 479491.

Seither, M., Wrage-Mönnig, N. \& Isselstein, J. 2014. Biomass production of LolioCynosuretum grassland is not increased by plant-species richness. Journal of Plant Nutrition and Soil Science, 177, 613-623.

Selbie, D.R., Buckthought, L.E. \& Shepherd, M.A. 2015. The challenge of the urine patch for managing nitrogen in grazed pasture systems. Advances in Agronomy, 129, 229-292.

Shand, C., Williams, B.L., Dawson, L.A., Smith, S. \& Young, M.E. 2002. Sheep urine affects soil solution nutrient composition and roots: Differences between field and sward box soils and the effects of synthetic and natural sheep urine. Soil Biology and Biochemistry, 34, 163-171.

Shand, C.A., Williams, B.L., Smith, S. \& Young, M.E. 2000. Temporal changes in C, P and N concentrations in soil solution following application of synthetic sheep urine to a soil under grass. Plant and Soil, 222, 1-13.

Venables, W.N. \& Ripley, B.D. 2002. Modern applied statistics with S-Plus, 2nd ed. Springer New York.

Vinther, F.P. 1998. Biological nitrogen fixation in grass-clover affected by animal excreta. Plant and Soil, 203, 207-215.

Whitehead, D.C. 1995. Grassland nitrogen. CAB International Wallingford.

Whitehead, D.C. 2000. Nutrient elements in grassland: Soil-plant-animal relationships. CAB International Wallingford. 
White-Leech, R., Liu, K., Sollenberger, L.E., Woodard, K.R. \& Interrante, S.M. 2013a. Excreta deposition on grassland patches. I. Forage harvested, nutritive value, and nitrogen recovery. Crop Science, 53, 688-695.

White-Leech, R., Liu, K., Sollenberger, L.E., Woodard, K.R. \& Interrante, S.M. 2013b. Excreta deposition on grassland patches. II. Spatial pattern and duration of forage responses. Crop Science, 53, 1-8.

Williams, P.H., Gregg, P.E.H. \& Hedley, M.J. 1990. Fate of potassium in dairy cow urine applied to intact soil cores. New Zealand Journal of Agricultural Research, 33, 151158.

Williams, P.H. \& Haynes, R.J. 1994. Comparison of initial wetting pattern, nutrient concentrations in soil solution and the fate of ${ }^{15} \mathrm{~N}$-labelled urine in sheep and cattle urine patch areas of pasture soil. Plant and Soil, 162, 49-59.

Williams, P.H. \& Haynes, R.J. 1995. Effect of sheep, deer and cattle dung on herbage production and soil nutrient content. Grass and Forage Science, 50, 263-271. 
Chapter III:

Small-scale sward heterogeneity rather than variable nutrient application rates in excrements determined plant nutrient concentration in a low-input pasture

Scheile T., Isselstein J., Tonn B. 


\begin{abstract}
In grazed pastures dung and urine patches of grazers provide variable amounts of nutrients for pasture vegetation growth. For low-input conditions there is no information on vegetation nutrient response to varying nutrient application rates with excrements. In this study urine and dung of cattle and sheep, derived from an adjacent rotational grazing system, were artificially placed on low-input diverse permanent grassland swards in spring. Cattle excrements were also applied in summer and autumn. Excrement nitrogen and potassium concentration were analysed prior the application. Additionally, untreated and fertilized swards, representing the mean nutrient return by grazing animals, were realized. Aboveground plant biomass was sampled according to the rotational grazing system and its nitrogen and potassium concentration was determined. Nitrogen concentration in urine was very low for all application times. Urine and dung showed a great variability of nitrogen and potassium concentration, which was independent from grazer species and excrement sampling time. Nitrogen and potassium concentration of plant biomass in untreated swards varied widely. Increasing nitrogen application rates with excrements significantly decreased the plant biomass nitrogen concentration. Potassium application rates did not influence plant biomass nitrogen concentration and plant biomass potassium concentration was unaffected by either different potassium or nitrogen application rates. The great variability of excrement and plant biomass nutrient concentration suggests that heterogeneity of biomass nutrient concentrations in lowinput pastures may not necessarily be induced by the spatial heterogeneous excrement deposition of the grazers.
\end{abstract}

Keywords: Excrement; Low-input; Nutrient; Pasture; Response 


\section{Introduction}

Grazing animals separate and concentrate nutrients within the small area of urine and dung patches (Afzal \& Adams, 1992; Auerswald et al., 2010). Grazing animal species (Haynes \& Williams, 1993), animal-specific characteristics (Hoogendoorn et al., 2010) and the quality of ingested forage (Whitehead, 2000) influence the nutrient concentration and thus the amount of nutrients returned with excrements. In low-input pasture systems, quality of ingested forage varies with grazing selectivity (Villalba \& Provenza, 2009; Cuchillo Hilario et al., 2017) due to the botanically diverse sward composition (Rook et al., 2004). The separation of nutrients in urine and dung and the seasonally non-uniform deposition of the excrements furthermore alter the nutrient availability (Haynes \& Williams, 1993; White-Leech et al., 2013; Bélanger et al., 2015). Consequently, in low-input systems, in which nutrient cycling is primarily mediated by excrements, excrements represent a variable nutrient supply for pasture vegetation.

The diverse botanical composition in low-input pastures (Rook et al., 2004) species-dependent differences in nutrient acquisition ability (Moir et al., 2013) and different stages of plant maturity present at the sward may alter the plant biomass nutrient response to excrements. Plant nutrient response to excrements can therefore be expected to be highly variable in the systems. To our knowledge there is no study investigating the response of plant biomass nutrient concentration to different nutrient application rates with excrements in a low-input pasture system.

We therefore performed an experiment simulating rotational stocking and excrement return on a low-input pasture. Excrements were derived from cattle and sheep rotationally grazing a lowinput pasture with the same sward botanical composition and excrement nitrogen $(\mathrm{N})$ and potassium $(\mathrm{K})$ concentration was analysed. Experimental course closely followed this rotational stocking system. Cattle and sheep urine and dung were applied in spring and cattle excrements were applied in summer and autumn. In addition, an untreated control and a fertilized control representing the mean nutrient return of grazing animals were established. Aboveground plant biomass was sampled in the grazing rotation subsequent to the excrement application and its $\mathrm{N}$ and $\mathrm{K}$ concentration was analysed. The underlying hypothesis was that due to the low-input system, increasing $\mathrm{N}$ and $\mathrm{K}$ application rates with both urine and dung, will increase plant biomass nutrient concentration. 


\section{Material and Methods}

The experimental area is situated in the Solling Uplands, Germany (51 $\left.46^{\circ} 47 \mathrm{~N}, 9^{\circ} 42^{\prime} 11 \mathrm{E}\right)$ and its vegetation belongs to the plant association of a moderately species-rich Lolio-Cynosuretum. It consisted of 48 square plots split into four blocks, with a sampling area of $1 * 1 \mathrm{~m}^{2}$ for cattle and $0.5 * 0.5 \mathrm{~m}^{2}$ for sheep and control plots.

The treatments sheep, cattle urine and dung, untreated and fertilized control were realized. Times of excrement application and plant biomass sampling were based on a reference grazing experiment on nearby paddocks with the same sward botanical composition, which was run as a rotational stocking system with three rotations (spring, summer, winter). Sheep excrements were applied in spring and cattle excrements were applied in all stocking rotations. Directly before each application, fresh urine and dung were collected from cattle (adult, non-lactating suckler cows of the breed German Simmental) or sheep (adult, non-lactating Blackheaded sheep ewes) grazing the reference experiment. Excrement application rates and areas covered were chosen according to Haynes \& Williams (1993) so the nutrient application rates with excrements were as shown in Table 1 . The urine was spread inside a metal ring with a diameter of $0.7 \mathrm{~m}$ and $0.42 \mathrm{~m}$ for cattle $(2 \mathrm{l})$ and sheep $(0.15 \mathrm{l})$ respectively. Dung application rate was $2 \mathrm{~kg}$ of cattle dung or $0.1 \mathrm{~kg}$ of sheep dung, which was placed in the centre of the sampling area. The fertilized control received $15.0 \mathrm{~g}$ nitrogen $(\mathrm{N}), 2.25 \mathrm{~g}$ phosphorus $(\mathrm{P})$ and $17.1 \mathrm{~g}$ potassium $(\mathrm{K}) \mathrm{m}^{-2}$ as mineral fertilizer, equally shared between the three application times to represent mean nutrient return by grazing animals.

Table 1 Nutrient application rates for cattle and sheep urine and dung at three application times.

\begin{tabular}{cccccc}
\hline \multirow{2}{*}{ Animal species } & \multirow{2}{*}{ Application time } & \multicolumn{2}{c}{ Urine } & \multicolumn{2}{c}{ Dung } \\
\cline { 3 - 6 } & & $\mathrm{N}\left(\mathrm{g} \mathrm{m}^{-2}\right)$ & $\mathrm{K}\left(\mathrm{g} \mathrm{m}^{-2}\right)$ & $\mathrm{N}\left(\mathrm{g} \mathrm{m}^{-2}\right)$ & $\mathrm{K}\left(\mathrm{g} \mathrm{m}^{-2}\right)$ \\
\hline Cattle & Spring 2015 (01-08/06) & 9.4 & 3.7 & 7.0 & 2.3 \\
Sheep & & 1.0 & 3.7 & 2.2 & 1.5 \\
\hline Cattle & Summer 2015 (16/07) & 2.4 & 28.7 & 5.4 & 2.5 \\
\hline Cattle & Autumn 2015 (30/09) & 2.8 & 8.1 & 8.8 & 2.7
\end{tabular}


Aboveground plant biomass was cut to a vegetation height of $2 \mathrm{~cm}$ using electric scissors at the next stocking rotation of the reference experiment that followed the excrement application. Thus the time of biomass sampling represented the next utilization of the pasture. $\mathrm{K}$ concentration of the samples was determined after digestion with aqua regia using an Inductively Coupled Plasma 6300 DUO ICP OMS (Thermo Fisher Corporation, Waltham) and $\mathrm{N}$ was determined according to the Dumas combustion method using a Variomax $\mathrm{CN}$ analyser (Elementar Analysesysteme GmbH, Hanau).

Statistical analysis

The statistical analysis was performed using the program $\mathrm{R}$ version 3.2.0 (R Core Team, 2015). The data for all application times were analysed as a combined dataset. Influence of $\mathrm{N}$ and $\mathrm{K}$ application rates with the excrements on $\mathrm{N}$ or $\mathrm{K}$ concentration in plant biomass was tested using linear fixed effect models implemented in the package nlme (Pinheiro et al., 2015). The models had the fixed effects $\mathrm{N}$ or $\mathrm{K}$ application rate. 


\section{Results and Discussion}

The nutrient application rates with urine and dung showed great differences between animal species and single application times (Table 1). Dung $\mathrm{N}$ and $\mathrm{K}$ concentration ranged between 20.3-27.3 $\mathrm{g} \mathrm{kg}^{-1}$ and 7.8-18.9 $\mathrm{g} \mathrm{kg}^{-1}$ (both $\mathrm{N}$ and $\mathrm{K}$ concentration on dry matter basis). In urine, 1.15-4.67 $\mathrm{g} \mathrm{l}^{-1} \mathrm{~N}$ and 1.84-14.33 $\mathrm{g} \mathrm{l}^{-1} \mathrm{~K}$ were found. A comparison of these data with concentrations reported by others showed that dung $\mathrm{N}$ and $\mathrm{K}$ concentrations in our study were within the range reported, but urine $\mathrm{N}$ concentrations, which showed by far the greatest variance, were much lower than reported average values (Haynes \& Williams, 1993; Whitehead, 2000; Dijkstra et al., 2013).

The $\mathrm{N}$ concentration in urine is influenced by forage $\mathrm{N}$ concentration, as the proportion of $\mathrm{N}$ excreted in urine increases with $\mathrm{N}$ concentration of ingested forage (Whitehead, 1995). An analysis of plant biomass nutrient concentration of the reference experiment at the times of excrement collection indicated of as little as $13.1 \mathrm{mg} \mathrm{g}^{-1} \mathrm{~N}$ and $24.6 \mathrm{mg} \mathrm{g}^{-1} \mathrm{~K}$, which could have caused the low urine $\mathrm{N}$ concentrations (Whitehead, 1995). The impact of the diverse pasture in the reference experiment on grazing selectivity (Cuchillo Hilario et al., 2017) and different stages of plant maturity present in these pastures could have altered the digestibility of herbage ingested and thus increased variability of excrement nutrient concentration (Bruinenberg et al., 2002). So even though animals were grazing the same pasture, the nutrient concentration in urine and dung and thus the amount of nutrients returned via excrements by the 5 cattle and 30 sheep was very variable in the low-input system of the current study.

The statistical analysis on the plant $\mathrm{N}$ and $\mathrm{K}$ concentration response to different nutrient application rates with excrements was performed independently from time of application, excrement type and animal species in order to observe the general effect of nutrient application on plant biomass nutrient concentration. We generally found a great variability of plant nutrient concentrations within the different $\mathrm{N}$ and $\mathrm{K}$ application rates (Fig.1). Only the $\mathrm{N}$ application rate significantly affected the plant nutrient concentration, with increasing $\mathrm{N}$ application rates resulting in a significant decrease $(P=0.0243)$ of the plant $\mathrm{N}$ concentration. 

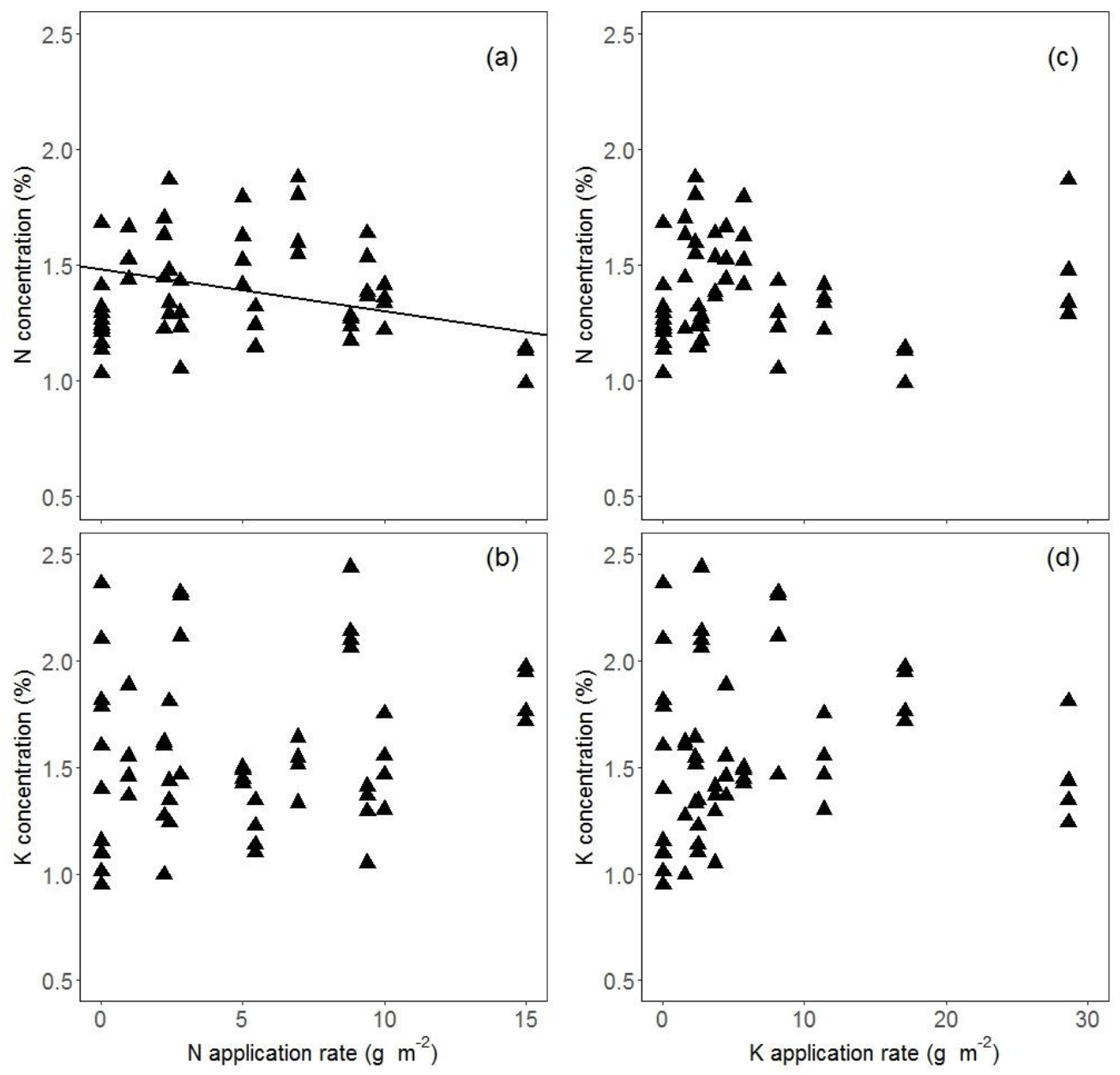

Figure 1. Effect of $\mathrm{N}$ application rate $\left(\mathrm{g} \mathrm{m}^{-2}\right)$ on the plant biomass $\mathrm{N}$ (a) and plant $\mathrm{K}$ concentration (b). Effect of $\mathrm{K}$ application rate $\left(\mathrm{g} \mathrm{m}^{-2}\right)$ on the plant $\mathrm{N}(\mathrm{c})$ and plant biomass $\mathrm{K}$ concentration (d). The line in figure (a) indicates the significant relationship $(P<0.05)$ between $\mathrm{N}$ concentration in plant biomass and $\mathrm{N}$ application rate.

A high variability in plant nutrient concentration was measured even for the unfertilized control. Plant nutrient concentration therefore seemed to be independent from the general presence of excrements. As a result, the overall high variability of plant biomass $\mathrm{N}$ concentration may reduce the interpretability of the effect found for increasing $\mathrm{N}$ application rates. Thus the high variability in plant nutrient concentration found for the broad range of nutrient application rates falsifies our hypothesis.

In a grazed pasture, nutrient utilization from excrements and subsequent acquisition by plants is a complex process depending on both nutrient mineralization from excrements, influenced by form and time of excrement deposition (Whitehead, 2000; Bélanger et al., 2015), and on the current plant nutrient demand at the time of excrement deposition (Bélanger et al., 2015). 
However, for a low-input pasture our results showed that these processes did not play a role at the small scale of the excrement patch. The results also suggest that the plant nutrient concentration was independent from the nutrient application rate. This leads to the hypothesis that the spatially heterogeneous sward structure in low-input pastures may not be entirely conditioned by soil spatial heterogeneity caused by grazing animals (Liu et al., 2016). The high variability of plant biomass nutrient concentrations found for the untreated control may support this hypothesis.

To our knowledge this is the first study observing plant biomass nutrient response to a broad range of excrement nutrient application rates in a diverse low-input pasture system. In conclusion, we found high variability for the excrement nutrient concentration and hence nutrient application rates, which may be even higher under real grazing conditions (Haynes \& Williams, 1993). Plant biomass nutrient concentration varied strongly with little influence of nutrient application rates. Factors other than spatially heterogeneous excrement deposition seem to be important for small-scale variation of plant biomass nutrient concentration under low-input conditions. 


\section{References}

Afzal, M. \& Adams, W.A. 1992. Heterogeneity of soil mineral nitrogen in pasture grazed by cattle. Soil Science Society of America Journal, 56, 1160-1166.

Auerswald, K., Mayer, F. \& Schnyder, H. 2010. Coupling of spatial and temporal pattern of cattle excreta patches on a low intensity pasture. Nutrient Cycling in Agroecosystems, $88,275-288$.

Bélanger, G., Rochette, P., Chantigny, M., Ziadi, N., Angers, D., Charbonneau, É., Pellerin, D. \& Liang, C. 2015. Nitrogen availability from dairy cow dung and urine applied to forage grasses in eastern Canada. Canadian Journal of Plant Science, 95, 55-65.

Bruinenberg, M.H., Valk, H., Korevaar, H. \& Struik, P.C. 2002. Factors affecting digestibility of temperate forages from seminatural grasslands: A review. Grass and Forage Science, 57, 292-301.

Cuchillo Hilario, M., Wrage-Mönnig, N. \& Isselstein, J. 2017. Behavioral patterns of $\quad$ (cograzing cattle and sheep on swards differing in plant diversity. Applied Animal Behaviour Science, 191, 17-23.

Dijkstra, J., Oenema, O., van Groenigen, J.W., Spek, J.W., van Vuuren, A.M. \& Bannink, A. 2013. Diet effects on urine composition of cattle and $\mathrm{N}_{2} \mathrm{O}$ emissions. Animal: $\mathrm{An}$ International Journal of Animal Bioscience, 7, 292-302.

Haynes, R.J. \& Williams, P.H. 1993. Nutrient cycling and soil fertility in the grazed pasture ecosystem. Advances in Agronomy, 49, 119-199.

Hoogendoorn, C.J., Betteridge, K., Costall, D.A. \& Ledgard, S.F. 2010. Nitrogen concentration in the urine of cattle, sheep and deer grazing a common ryegrass/cocksfoot/white clover pasture. New Zealand Journal of Agricultural Research, 53, 235-243.

Liu, C., Song, X., Wang, L., Wang, D., Zhou, X., Liu, J., Zhao, X., Li, J., Lin, H. \& Wan, S. 2016. Effects of grazing on soil nitrogen spatial heterogeneity depend on herbivore assemblage and pre-grazing plant diversity. Journal of Applied Ecology, 53, 242-250.

Moir, J.L., Edwards, G.R. \& Berry, L.N. 2013. Nitrogen uptake and leaching loss of thirteen temperate grass species under high N loading. Grass and Forage Science, 68, 313 325 . 
Pinheiro, J., Bates, D, Debroy, S, Sarkar, D \& R Core Team. 2015. nlme: Linear and nonlinear mixed effects models, R package version 3.1-120, Aivailable at: http://CRAN.Rproject.org/package=nlme.

R Core Team. 2015. R: A language and environment for statistical computing. R Foundation for Statistical Computing, Vienna, Austria: Available at: http://www.R-project.org/.

Rook, A.J., Dumont, B., Isselstein, J., Osoro, K., WallisDeVries, M.F., Parente, G. \& Mills, J. 2004. Matching type of livestock to desired biodiversity outcomes in pastures - a review. Biological Conservation, 119, 137-150.

Villalba, J.J. \& Provenza, F.D. 2009. Learning and dietary choice in herbivores. Rangeland Ecology \& Management, 62, 399-406.

Whitehead, D.C. 1995. Grassland nitrogen. CAB International Wallingford.

Whitehead, D.C. 2000. Nutrient elements in grassland: soil-plant-animal relationships. CAB International Wallingford.

White-Leech, R., Liu, K., Sollenberger, L.E., Woodard, K.R. \& Interrante, S.M. 2013. Excreta deposition on grassland patches. I. Forage harvested, nutritive value, and nitrogen recovery. Crop Science, 53, 688-695. 


\section{General Discussion}

The aim of the present study was to evaluate the effect of grazing animal species and pasture sward botanical composition on nutrient cycling in a low-input semi-natural grazing system. For this purpose two field experiments were conducted: one grazing experiment and one simulating rather realistic grazing conditions (simulation experiment). These experiments were performed to enable an examination of excrement effects from different perspectives. Both the plant biomass production and the plant nutrient concentration on different sward types (diverse and grass-dominated) and grazing animal forage uptake (cattle and sheep) at urine and dung patches were analysed in a grazed pasture of the grazing experiment. Two observation periods were realized in this experiment: Grazing and excrement deposition in spring with regrazing in summer and grazing and excrement deposition in autumn with regrazing in spring of the following year. The course of the simulation experiment was adapted to that of the grazing experiment. Excrements from the grazing experiment were applied according to the stocking rotations of the grazing experiment. Cattle and sheep urine and dung were applied on both grassdominated and diverse swards in spring, whereas cattle excrements were additionally applied in summer and autumn on diverse swards. Aboveground plant biomass production and nutrient concentration were sampled in the course of the grazing season. Additionally, soil nutrients directly below and around excrement patches and belowground biomass were sampled at the end of the season.

Nutrient cycling in grazed low-input pastures is mainly mediated by excrements of the grazing animals (Rotz et al., 2005). The excrements alter the plant biomass production and nutrient concentration (Williams \& Haynes, 1995; White-Leech et al., 2013a; Marsden et al., 2016) which results in areas being temporally favoured (Day \& Detling, 1990; Steinauer \& Collins, 2001) or avoided (Smith et al., 2009; Gillet et al., 2010). They are therefore the central point of nutrient cycling in this system.

I will now discuss the results of this study concerning the following questions: What effects do animal- and sward-specific responses to excrements have on nutrient cycling within the stocking period subsequent to different excrement deposition times? How strong is the mediumterm effect of nutrient separation in urine and dung on plant biomass production and soil nutrient status? To what extent does the plant biomass nutrient concentration respond to varying excrement nutrient application rates present in a real grazing system? 
In my investigation, the analysis of plant biomass data revealed that the excrement effect on plant biomass differed between the stocking period and a complete grazing season following the excrement deposition. In the grazing experiment (Chapter I) there was a general effect of urine patches significantly increasing the plant biomass production as well as $\mathrm{N}$ and $\mathrm{K}$ content and of dung patches significantly increasing the plant biomass $\mathrm{K}$ content. The results indicated no differences in the effect of excrements on plant biomass within the stocking period subsequent to the excrement deposition in spring and autumn. The stocking periods differed in terms of weather conditions and resting intervals between excrement deposition and plant biomass sampling. Other studies have shown clear differences in the plant biomass production following excrement application in spring and autumn (Moir et al., 2011; Bélanger et al., 2015), which could be attributed to a lower plant nutrient demand for excrement application times later in the year. Therefore, the missing difference in plant biomass response to the excrements between the two stocking periods led to the assumption, that plant nutrient uptake from excrements and thus plant productivity may be, to a certain point, limited by the ability of plant biomass to utilize the nutrients supplied in the low-input system of the current study. The fact that the effect of urine patches on plant parameters in this study was by far lower than it has been reported even for intensively used pastures (Williams \& Haynes, 1994; White-Leech et al., 2013a, b; Marsden et al., 2016) may support this theory.

The plant biomass $\mathrm{N}$ and $\mathrm{K}$ concentration following the application of different $\mathrm{N}$ and $\mathrm{K}$ application rates through excrements (Chapter III) gave further explanation for the low response of plant biomass to the excrements. It showed a high variability of plant biomass nutrient concentration which was independent from the nutrient application rates through excrements. Even plant biomass $\mathrm{N}$ and $\mathrm{K}$ concentration of the untreated control varied greatly which implied that the very old, naturally developed grassland sward in this study may have caused the high variability at the small scale of the excrement patches. This may furthermore be an explanation for the missing effect of excrement deposition time on plant parameters sampled. An acquisition of the nutrient uptake ability of plant species present (Moir et al., 2013) and shorter periods between excrement deposition and plant sampling (Moir et al., 2011) would give further information on the low plant biomass response to excrements.

The analysis of the urine and dung nutrient concentrations (Chapter III) showed a generally high variability for both cattle and sheep excrements for different sampling times and sward types. Since the sampling area of cattle $\left(1 \mathrm{~m}^{2}\right)$ and sheep $\left(0.25 \mathrm{~m}^{2}\right)$ corresponded to the same 
ratio between the natural excrement patch and the rest of the sampling area, the missing difference in animal specific effects on plant production and nutrient concentration may be attributed to the lack of difference in excrement nutrient concentration (Hoogendoorn et al., 2010). Moreover, it can be assumed that besides the nutrient concentration, the amount of excrements returned to the sward varied greatly as well throughout in the grazing experiment (Haynes \& Williams, 1993; Whitehead, 2000). This could have promoted the variability found for the plant biomass nutrient concentration. The analysis of forage residue at the excrement patches, used as an indicator of grazer forage uptake at the excrements showed a significant increase in forage residue at the dung patches of both cattle and sheep following both excrement deposition in spring and autumn. In general grazers avoid grazing at dung patches (Smith et al., 2009). The additional lack of preference for urine patches (Day \& Detling, 1990; Steinauer \& Collins, 2001) led to the assumption that within the stocking period, subsequent to the excrement deposition, plant biomass and thus nutrients at the excrement patches are not being reused by the grazing animals. Plant biomass is therefore rather left for decomposition and may thus be cycled through the litter cycle (Bardgett \& Wardle, 2003). However, the difference in grazing avoidance in close vicinity to the dung patches, which was stronger for cattle than for sheep, as indicated by the vegetation height measurement, may lead to a change in composition and structure of vegetation growing at cattle dung patches (Gillet et al., 2010). This depends on the period of dung rejection, which was reported to last up to 18 months for cattle (Haynes \& Williams, 1993).

Considering the second question (Chapter II), the cattle urine patches significantly increased the plant production on grass-dominated swards following application in spring. These findings are in line with other studies reporting a positive effect of cattle urine patches on plant production up to four months following the application (White-Leech et al., 2013b) and multiple cuttings (Bélanger et al., 2015). The significantly increased soil $\mathrm{NO}_{3}{ }^{-}$concentration at cattle and sheep urine patches indicated that the urine $\mathrm{N}$ supply exceeded the limited plant biomass $\mathrm{N}$ uptake over the season. The dung patches of cattle and sheep had no negative effect on plant production on grass-dominated swards. Jørgensen \& Jensen (1997) reported that in grass-legume mixtures the $\mathrm{N}$, mineralized from dung, was predominantly taken up by grass, which may be an explanation for the increased plant production on grass-dominated swards in the current study. The application of dung patches of both cattle and sheep on diverse swards resulted in a negative effect on plant production. For cattle dung patches a negative effect on 
plant production over 112 days has been reported (White-Leech et al., 2013b). Therefore the results of the current study indicated that dung patches did not only affect the area covered (Dai, 2000), but also the vegetation surrounding the dung patches. Sheep dung patches were completely decomposed and significantly increased soil $\mathrm{NO}_{3}{ }^{-}$concentration, which implied a mineralization of inorganic $\mathrm{N}$ in dung and hence an increase of plant-available $\mathrm{N}$ (Deenen \& Middelkoop, 1992; Haynes \& Williams, 1993). In contrast to other studies (Williams \& Haynes, 1995; Ma et al., 2007) the findings of the current study indicated a negative effect of sheep dung on plant production for a period of four months following application. The dung patches of cattle represented a source of extractable $\mathrm{P}$ and $\mathrm{K}$ directly below the patch and also for $\mathrm{NH}_{4}{ }^{+}$ and $\mathrm{NO}_{3}{ }^{-}$in both sampling areas at the end of the grazing season which indicated that a mineralization of $\mathrm{N}$ took place in the course of the experiment (Deenen \& Middelkoop, 1992; Haynes \& Williams, 1993). The adverse effect of dung smothering on grass growth may have lowered the plant nutrient uptake (Cai \& Akiyama, 2016).

Cattle urine and dung application later in the year (summer and autumn) did not affect the production of subsequently growing plant biomass. This was similar to the application in spring where the effect of cattle excrements was also small on the diverse sward. Missing differences of soil $\mathrm{N}$ concentration between excrements and untreated control implied that $\mathrm{N}$ from excrements were lost, for example by leaching over winter (Saarijärvi \& Virkajärvi, 2009), rather than utilized by pasture vegetation. Due to the experimental procedure of the simulation experiment, nutrient losses could not be quantified. However, decomposition of dung in the following winter implied N mineralization (Deenen \& Middelkoop, 1992; Haynes \& Williams, 1993), yet the soil $\mathrm{N}$ status was not affected. Thus the results indicated that in rotationally grazed low-input systems the excrement deposition by grazers and current plant nutrient demand did not necessarily overlap. Moreover, the differences in nutrient availability of dung and urine (Whitehead, 2000) did only affect plant production on grass-dominated swards.

My investigation has shown that the sward botanical composition, the grazing animal species and the time of grazing did not alter the effect of urine and dung patches on plant biomass within the stocking period subsequent to the excrement deposition. In terms of the excrement effect throughout a whole grazing season, grass-dominated patches caused a higher productivity at cattle urine patches. The results showed an overall low response of plant biomass production to excrements and moreover indicated a high variability in plant nutrient concentration which may be an explanation for the heterogeneous sward structure of the low-input system used in this 
study. Additionally, the higher grazing avoidance by cattle than by sheep in close vicinity to the dung patches increases this heterogeneity. Further investigations of nutrient losses at the excrement patches as well as shorter periods between excrement deposition and plant biomass sampling (Moir et al., 2011) would give more information on nutrient cycling in this system. 


\section{References}

Bardgett, R.D. \& Wardle, D.A. 2003. Herbivore-mediated linkages between aboveground and belowground communities. Ecology, 84, 2258-2268.

Bélanger, G., Rochette, P., Chantigny, M., Ziadi, N., Angers, D., Charbonneau, É., Pellerin, D. \& Liang, C. 2015. Nitrogen availability from dairy cow dung and urine applied to forage grasses in eastern Canada. Canadian Journal of Plant Science, 95, 55-65.

Cai, Y. \& Akiyama, H. 2016. Nitrogen loss factors of nitrogen trace gas emissions and leaching from excreta patches in grassland ecosystems: A summary of available data. The Science of the Total Environment, 572, 185-195.

Dai, X. 2000. Impact of cattle dung deposition on the distribution pattern of plant species in an alvar limestone grassland. Journal of Vegetation Science, 11, 715-724.

Day, T.A. \& Detling, J.K. 1990. Grassland patch dynamics and herbivore grazing preference following urine deposition. Ecology, 71, 180-188.

Deenen, P. \& Middelkoop, N. 1992. Effects of cattle dung and urine on nitrogen uptake and yield of perennial ryegrass. Netherlands Journal of Agricultural Science, 40, 469-482.

Gillet, F., Kohler, F., Vandenberghe, C. \& Buttler, A. 2010. Effect of dung deposition on smallscale patch structure and seasonal vegetation dynamics in mountain pastures. Agriculture, Ecosystems \& Environment, 135, 34-41.

Haynes, R.J. \& Williams, P.H. 1993. Nutrient cycling and soil fertility in the grazed pasture ecosystem. Advances in Agronomy, 49, 119-199.

Hoogendoorn, C.J., Betteridge, K., Costall, D.A. \& Ledgard, S.F. 2010. Nitrogen concentration in the urine of cattle, sheep and deer grazing a common ryegrass/cocksfoot/white clover pasture. New Zealand Journal of Agricultural Research, 53, 235-243.

Jørgensen, F.V. \& Jensen, E.S. 1997. Short-term effects of a dung pat on $\mathrm{N}_{2}$ fixation and total $\mathrm{N}$ uptake in a perennial ryegrass/white clover mixture. Plant and Soil, 196, 133-141.

Ma, X., Wang, S., Jiang, G., Haneklaus, S., Schnug, E. \& Nyren, P. 2007. Short-term effect of targeted placements of sheep excrement on grassland in Inner Mongolia on soil and plant parameters. Communications in Soil Science and Plant Analysis, 38, 1589-1604.

Marsden, K.A., Jones, D.L. \& Chadwick, D.R. 2016. Disentangling the effect of sheep urine patch size and nitrogen loading rate on cumulative $\mathrm{N}_{2} \mathrm{O}$ emissions. Animal Production Science, 56, 265-275. 
Moir, J.L., Cameron, K.C., Di, H.J. \& Fertsak, U. 2011. The spatial coverage of dairy cattle urine patches in an intensively grazed pasture system. The Journal of Agricultural Science, 149, 473-485.

Moir, J.L., Edwards, G.R. \& Berry, L.N. 2013. Nitrogen uptake and leaching loss of thirteen temperate grass species under high N loading. Grass and Forage Science, 68, 313325.

Rotz, C.A., Taube, F., Russelle, M.P., Oenema, J., Sanderson, M.A. \& Wachendorf, M. 2005. Whole-farm perspectives of nutrient flows in grassland agriculture. Crop Science, 45, 2139-2159.

Saarijärvi, K. \& Virkajärvi, P. 2009. Nitrogen dynamics of cattle dung and urine patches on intensively managed boreal pasture. The Journal of Agricultural Science, 147, 479491.

Smith, L.A., White, P.C., Marion, G. \& Hutchings, M.R. 2009. Livestock grazing behavior and inter- versus intraspecific disease risk via the fecal-oral route. Behavioral Ecology, 20, $426-432$.

Steinauer, E.M. \& Collins, S.L. 2001. Feedback loops in ecological hierarchies following urine deposition in tallgrass prairie. Ecology, 82, 1319-1329.

Whitehead, D.C. 2000. Nutrient elements in grassland: soil-plant-animal relationships. CAB International Wallingford.

White-Leech, R., Liu, K., Sollenberger, L.E., Woodard, K.R. \& Interrante, S.M. 2013a. Excreta deposition on grassland patches. I. Forage harvested, nutritive value, and nitrogen recovery. Crop Science, 53, 688-695.

White-Leech, R., Liu, K., Sollenberger, L.E., Woodard, K.R. \& Interrante, S.M. 2013b. Excreta deposition on grassland patches. II. Spatial pattern and duration of forage responses. Crop Science, 53, 1-8.

Williams, P.H. \& Haynes, R.J. 1994. Comparison of initial wetting pattern, nutrient concentrations in soil solution and the fate of ${ }_{15} \mathrm{~N}$-labelled urine in sheep and cattle urine patch areas of pasture soil. Plant and Soil, 162, 49-59.

Williams, P.H. \& Haynes, R.J. 1995. Effect of sheep, deer and cattle dung on herbage production and soil nutrient content. Grass and Forage Science, 263-271. 


\section{Summary}

Excrements of grazing animals play a key role for nutrient cycling in grazed grasslands. So far, most studies on nutrient cycling in pasture systems were performed using simulated excrement patches under simulated grazing conditions. Influences of both plant and animal functional traits on nutrient cycling are known for soil-to-plant-to-animal cycling steps, but relatively little is known about their effect on animal-to-soil-to-plant cycling steps. In low-input pastures excrements from grazing animals represent the main nutrient source for grassland vegetation. Plant and animal functional traits should therefore have a greater impact on nutrient cycling in these systems. For this approach the excrement patch is the functional scale at which nutrient cycling should be assessed in a grazed grassland.

In this study, I investigated grazing animal excrement patches to determine whether different plant and animal functional traits have an effect on plant biomass production, plant nutrient concentration and grazing animal selectivity under real grazing conditions in a grazing system with rotational stocking. Furthermore, I studied the medium-term effects of grazing animal excrements on the plant biomass, plant nutrient concentration and soil nutrient concentration under simulated conditions over a complete grazing season.

The experiments were performed in a semi-natural grassland, which corresponded to a moderately species-rich Lolio-Cynosuretum community. The site is located in the Solling Uplands (Germany / Lower Saxony). Two sward types were realized: a moderately species-rich (diverse) and a grass-dominated sward, achieved by selective herbicide application. In a grazing experiment, swards were rotationally grazed by cattle or sheep from spring to autumn. Excrements were marked in spring and autumn and plant biomass and vegetation height were sampled in the subsequent grazing rotation to cover both plant and animal response. Plant biomass nutrient concentration, production and grazing animal forage uptake at the excrement patches were not affected by the stocking periods, animal species and sward types in the grazing experiment. There was only a general effect of excrement patches on these factors. The results indicated an overall low response of the grassland vegetation to the excrements. Presence of urine patches increased plant biomass production as well as the nitrogen and potassium content of the forage. Dung patches increased the plant biomass potassium content and decreased the animal forage uptake. Regarding their gracing behaviour, clear differences could be seen between cattle and sheep in close vicinity to the dung patches. Cattle avoided grazing vegetation 
close to dung patches following both deposition in spring and in autumn and sheep only following dung deposition in spring. Furthermore, cattle preferentially grazed at urine plots of the grass-dominated swards.

A second experiment was realized with simulated grazing where excrements, derived from the grazing experiment, were applied and plant biomass was sampled according to three grazing rotations over the year. Additionally, soil nutrient status was sampled at the end of the simulated grazing season to cover the medium-term pasture response to excrements. In this simulation experiment, the excrements only affected the plant biomass production following application in spring without differences between animal species. Grass-dominated swards showed a higher production than diverse swards at plots receiving excrements. Dung patches decreased plant biomass production at the diverse swards and cattle urine patches increased plant biomass production at grass-dominated swards. Excrement nutrient concentration showed a great variability for both cattle and sheep and sampling date. The analysis of plant biomass nutrient concentration at the simulation experiment revealed a great variability of both plant biomass $\mathrm{N}$ and $\mathrm{K}$ concentration which was independent from the excrement nutrient concentration, time of excrement application and sward botanical composition. Soil nutrient status showed the greatest response to the application of excrements in spring. Cattle induced a higher soil nutrient concentration (nitrate, ammonium, potassium) than sheep. Cattle dung patches additionally increased the phosphorus concentration. Sheep dung and urine patches only affected the soil nitrate and ammonium concentration.

Our results indicate an overall low response of plant biomass parameters to the presence of grazing cattle and sheep excrements, whereby plant and animal functional traits did not alter the plant response at the excrement patch. In the low-input pasture, pasture vegetation and grazing animals showed a rather general response to the presence of excrement. The high variability found for excrement and plant biomass nutrient concentration and plant biomass production indicates the complexity of nutrient cycling in a real grazing system. At the smallscale of the excrement patch, this high variability is an important factor determining nutrient cycling. Assessing nutrient losses following excrement application and determining the nutrient use efficiency of pasture vegetation at the excrement patch scale should give more detailed information on nutrient cycling. 


\section{Presentations and Publications}

Scheile, T., Isselstein, J., Tonn, B. 2015. Beeinflussung des Biomassewachstums sowie der Selektivität von Weidetieren durch Exkrementstellen bei extensiver Beweidung. Mitteilung der Arbeitsgemeinschaft Grünland und Futterbau 16, 144-177. Including a poster presented at the AGGF 2015 in Aulendorf, Germany.

Scheile, T., Isselstein, J., Tonn, B. 2016. Einfluss von Exkrementstellen auf die Biomasseproduktivität sowie die Selektivität von Weidetieren bei extensiver Beweidung. Mitteilung der Arbeitsgemeinschaft Grünland und Futterbau 17, 97-99. Including a poster presented at the AGGF 2016 in Luxembourg City, Luxembourg.

Scheile, T., Isselstein, J., Tonn, B. 2016. Effect of excreta patches on biomass productivity and grazing selectivity in low-input pastures, Grassland Science in Europe 21, 470472.

Including a poster presented at the EFG 2017 in Trondheim, Norway.

Scheile, T., Isseltstein, J., Tonn, B. 2018. Herbage biomass and uptake under low-input grazing as affected by cattle and sheep excrement patches, Nutrient Cycling in Agroecosystems, doi:10.1007/s10705-018-9945-3. 


\section{Acknowledgements}

This project was funded by the Deutsche Forschungsgemeinschaft (DFG; TO 895/1-1).

First of all I would like to thank Prof. Dr. Johannes Isselstein for giving me the opportunity to work in his group, the excellent supervision and his helpful advices and comments on my work.

My special thanks go to Dr. Bettina Tonn for the motivating discussions, her untiring patience and encouraging support during this thesis and beyond. Thank you for always having an open ear and for sharing all your knowledge and ideas.

Furthermore I am grateful to Prof. Dr. Nicole Wrage-Mönnig for co-reviewing my thesis and to Prof. Dr. Klaus Dittert for being a member of my thesis committee.

I am very thankful to Anne Vor for the countless hours we spend in Relliehausen and for always keeping a cool head, when things got stressful.

I want to thank my student assistants Philipp Langehenke and David Saal for the participation in my investigations and for the enjoyable times beyond work.

Arne Oppermann, Knut Salzmann and the staff of the experimental farm in Relliehausen I thank for handling all aspects concerning the animals.

Moreover I thank my colleagues, especially Dorothee Ebeling, who got me into grassland science, Anja Schmitz and Dirk Koops ("Das Heidepack") for the countless funny coffee breaks and for making time here so enjoyable. My acknowledgements also go to my friends for taking my mind off work.

Above all I thank my parents Christina and Michael Scheile for their everlasting support, their trust in me and for giving me everything I needed to make it so far.

My sister Julia I thank for being there for me and for having an open ear, when things got stressful.

Last but not least I thank Hanna Rabe for joining me in this adventure with all its ups and downs. You make me see the good, when things seemed to be impossible. 